\title{
Physical Gelation of AB-Alternating Copolymers Made of Vinyl Phenol and Maleimide Units: Cooperation between Precisely Incorporated Phenol and Long Alkyl Pendant Groups ${ }^{\dagger}$
}

\author{
Kana Nishimori, ${ }^{a}$ Esther Cazares-Cortes, ${ }^{\mathrm{b}}$ Jean-Michel Guigner, ${ }^{\mathrm{c}}$ Francois Tournilhac ${ }^{\mathrm{b}}$ and Makoto Ouchi ${ }^{\mathrm{a}}$
} a. Department of Polymer Chemistry, Graduate School of Engineering, Kyoto University, Katsura Nishikyo-ku, Kyoto 615-8510, Japan
b. Molecular, Macromolecular Chemistry, and Materials, CNRS, ESPCI-Paris, PSL Research University, 10 rue Vauquelin 75005 Paris, France
c. Institut de Minéralogie, de Physique des Matériaux et de Cosmochimie, Sorbonne Université, CNRS, UMR 7590, IRD, MNHN, 4 place Jussieu, F-75005
Paris, France

Manuscript published in Polymer Chemistry 2019, 10, 2327-2336. DOI: 10.1039/C9PY00329K.

A series of alternating copolymers consisting of vinyl phenol and $n$-alkyl maleimide was synthesized via radical copolymerization of a protected styrene derivative with a functional maleimide monomer followed by the deprotection. The copolymers carrying long alkyl pendant such as $\mathrm{C}_{12} \mathrm{H}_{25}-$ or $\mathrm{C}_{18} \mathrm{H}_{37}-$ chains on the maleimide unit showed UCST-type thermal response in aromatic solvents and organogels were specifically formed upon cooling of the fluid solution prepared at higher temperature. Hydrogen bonding of the phenol units is crucial for the gelation and the gelation temperature and stiffness were tuneable by varying concentration, solvent and polymerization degree. Analyses by ${ }^{1} \mathrm{H}-\mathrm{NMR}$, linear rheology, WAXD, SANS and cryo-TEM gave the picture of vermicular self-assembled nano-objects formed through segregated and hydrogen-bonded packing by the precisely incorporated two units in alternating sequence.

\section{Introduction}

Radical copolymerization ${ }^{1}$ is useful for tuning properties of polymers, and indeed copolymers have been widely used as polymer materials. The arrangement of comonomer units in each chain and the composition distribution among chains are significant for understanding the aggregation behaviors and properties, and the occurrence of particular sequences in copolymer chains can be predicted to a certain degree from the reactivity ratios as well as the polymerization methodology (non-living vs living). For example, when two comonomers of reactivity ratios $\left(r_{1}=r_{2}=1\right)$ are employed in copolymerization, the product is an "ideal random copolymer" (Figure 1A). In this case, the two units (A and B) are randomly distributed in chains and composition distribution among chains exists although not so broad, regardless of polymerization methodology. On the other hand, when the reactivity ratios are deviated from 1, the resultant sequence depends on polymerization methodology: copolymerization with living polymerization system could give a "gradient copolymer" (B), in contrast to non-living system resulting in broad composition distribution, i.e., mixed copolymer chains of various composition ratios (C). Combinations with reactivity ratios of extremely different values (e.g., styrene and vinyl acetate) would hardly give copolymers. An exceptional but interesting combination is comonomer combination of zero reactivity ratios $\left(r_{1}=r_{2}=0\right)$. Such comonomers give an "alternating copolymer" (D), and most importantly the resultant chains are uniform in terms of sequence (i.e., no distribution of composition ratio). ${ }^{2,3}$

On the other hand, block copolymers form another category of copolymers (E) and they have been used for material applications, such as elastomers, drug delivery, etc. Self-assembly is induced under appropriate condition giving periodic structures in bulk (e.g.,
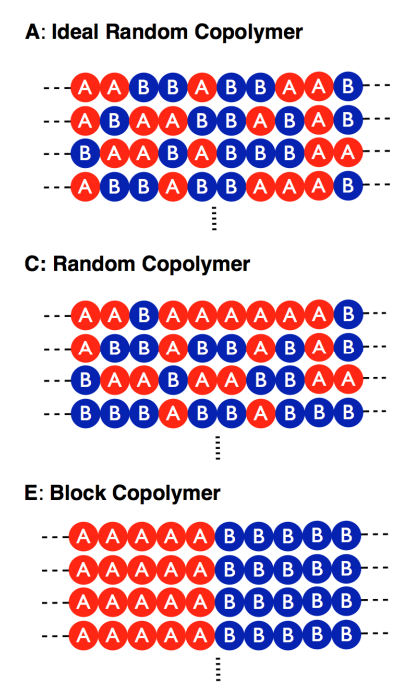

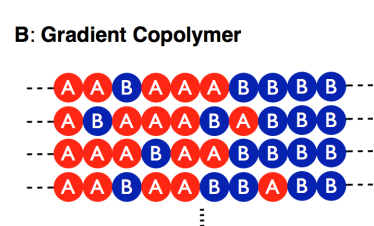

D: Alternating Copolymer

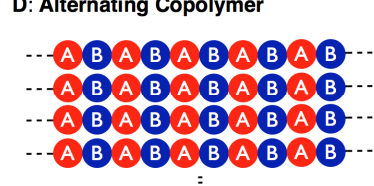

Fig. 1 Various copolymers: (A) ideal random copolymer; (B) gradient copolymer (C) random copolymer of broad composition distribution; (D) alternating copolymer; (E) block copolymer.

lamella, cylinder, and sphere) or solution (e.g., micelle, liposome, and bilayer sheet) so as to decrease the surface energy between different segments.4 Crucial of such self-assembly is compatibility or interaction between same chain segments (in other words, incompatibility between different segments). In general, such selfassembly is hardly expected using random copolymers, because the cohesion by randomly distributed comonomer units is much lower and weaker than with block segments. An exceptional example has been reported on self-assembly with random copolymer: methacrylate-based amphiphilic random copolymers carrying hydrophilic oligo(ethyleneglycol) and hydrophobic crystalline alkyl 


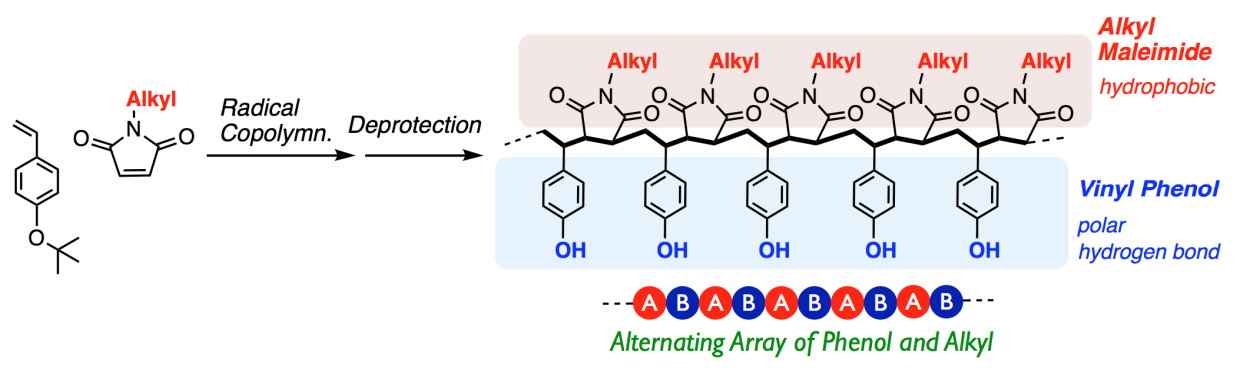

Fig. 2 Synthesis of alternating copolymer consisting of vinyl phenol and alkyl chain-substituted maleimide via radical copolymerization and deprotection for the styrene substituent.

pendants can undergo phase separation in the bulk state due to the extremely different characters of the two units. ${ }^{5}$

In this work, we studied self-assembly of alternating copolymer on the basis of the hypothesis that alternating copolymer chains of totally different properties (affinity, polarity, interaction, etc.) can effectively undergo cohesion or self-assembly. We thus selected a combination of tert-butoxy styrene (tBOS) with alkyl-pendant maleimide as the comonomers for radical copolymerization (Figure 2). Styrene (Sty) or the derivatives is known to induce alternating copolymerization with highly electron poor monomers such as maleic anhydride ${ }^{6}$ (MAnh) or maleimide derivatives. ${ }^{7}$ The combination was used recently to synthesize well defined graft copolymers by post functionalization of $\mathrm{p}$ (Sty-alt-MAnh) ${ }^{8}$ The alkoxy substituent on styrene is an electron-donating group, which is preferable for cross-over propagation. ${ }^{9}$ The tertbutoxy group can be deprotected under acidic condition giving rise to a phenol (i.e.,vinyl phenol) that is more polar and capable of hydrogen-bonding interaction, in contrast to the hydrophobic and non-polar alkyl pendant on the maleimide units. In addition, the rigid maleimide unit may be useful for segregation of the two different pendant groups. Thus, in this work, a series of alkyl maleimide-tBOS copolymers was synthesized in expectation of unique self-assembly.

Consequently, alternating copolymers consisting of vinyl phenol and alkyl chain $\left(\mathrm{C}_{12} \mathrm{H}_{25}\right.$ or $\left.\mathrm{C}_{18} \mathrm{H}_{37}\right)$-substituted maleimide were found to give physical gel in aromatic solvents. The fundamental feature for gelation is hydrogen bonding between regularly aligned phenol pendant groups, which was clarified by ${ }^{1} \mathrm{H}$ NMR and addition of stochiometric addition of pyridine. Effects of molecular weight and viscoelastic behaviors were also studied.

\section{Experimental}

\section{Materials}

Maleic anhydride (Wako; purity 99\%), $N$-octylamine (TCI; putiry >98\%), $\mathrm{N}$-dodecyl amine (TCI; purity 97\%), $\mathrm{N}$-octadecyl amine (Aldrich; purity 97\%), acetic anhydride (Wako; purity $>97 \%$ ), sodium acetate (Wako; purity >98.5\%), 2,2'azobisisobutyronitrile (AIBN, Wako; purity 98\%), 4-Cyano-4[(dodecylsulfanylthiocarbonyl)sulfanyl]pentanol

(Aldrich; purity >96.5\%), 1,4-dioxane (Wako, purity >99.5\%), $\mathrm{N}$ ethylmaleimide (EMI, TCI; purity >98\%), cumene (abcr $\mathrm{GmbH}$; purity 99\%), p-cymene (abcr $\mathrm{GmbH}$; purity 96\%), anisole (Aldrich; purity 99\%), xylene (Alfa Aesar, mixture of isomers; purity 98.5\%), 1,2,4-trichlorobenzene (CARLO ERBA; purity >98.5\%), nitrobenzene (RECTAPUR; purity 99.5\%), pyridine (Wako; purity $>99.5 \%$ ) and hydrochloric acid (Wako; 35 37\%) were used without purification. p-tertButoxystyrene (tBOS, Wako; purity >98\%) was distilled over calcium hydride before use. 1,2,3,4-Tetrahydronaphthalene (tetralin, Kishida Chemical; purity $>98 \%$ ), an internal standard in ${ }^{1} \mathrm{H}$ NMR, was dried over calcium chloride overnight and distilled twice over calcium hydride. Toluene (Kishida Kagaku, Osaka, Japan; purity 99.5\%) was dried and purified by passing through purification columns (Solvent Dispensing System, SG Water USA, Nashua, NH; Glass Counter).

\section{Characterization}

${ }^{1}$ H NMR: ${ }^{1} \mathrm{H}$ NMR spectra were recorded on a JEOL JNMECA500 spectrometer, operating at $500 \mathrm{MHz}$.

SEC: The molecular weight distributions of the polymers were measured by size exclusion chromatography (SEC) with tetrahydrofuran (THF) as an eluent on three polystyrene gel columns (Shodex KF-803; pore size, 20-1000 Å; $8.0 \mathrm{~mm}$ i.d. $30 \mathrm{~cm}$; flow rate $0.3 \mathrm{~mL} / \mathrm{min}$ ) connected to a DU-H2000 pump, a 74S-RI refractive index detector, and a 41-UV ultraviolet detector (all from Shodex). The columns were calibrated against 13 standard polystyrene samples (Polymer Laboratories; $\left.\mathrm{M}_{\mathrm{n}}=500-3840000 ; \mathrm{M}_{\mathrm{w}} / \mathrm{M}_{\mathrm{n}}=1.06-1.22\right)$ as well as the monomer.

FT-IR: FT-IR spectra of freeze dried alternating copolymers were measured by Agilent Cary 630 FTIR spectrometer (Agilent Technologies).

MALDI-TOF-MS: MALDI-TOF-MS analyses were performed on a ultraflex III (MALDI-TOF mass spectrometer, Bruker Daltonics) equipped with $337 \mathrm{~nm}$ nitrogen laser with dithranol or DCTB as matrix and sodium trifluoroacetate as cationizing agent.

Turbidity Measurement: Turbidity of the polymer solutions in toluene was measured on UV-1800 (Shimadzu, optical path length $=10 \mathrm{~mm}, 1=670 \mathrm{~nm}$, heating $/$ cooling rate: $1{ }^{\circ} \mathrm{C} / \mathrm{min}$, temperature range: $30-90{ }^{\circ} \mathrm{C}$ ). 
Rheology: Samples of 10wt\% Alt-C12 or Alt-C18 solutions in 1,2,4-trichlorobenzene were placed at $90{ }^{\circ} \mathrm{C}$ in the gap of an Anton Paar Physica MCR 501 rheometer equipped with a 50 mm diameter cone-plate geometry placed under a solvent trap and operating in the standard oscillatory mode. Samples were first annealed for 10 minutes at $90{ }^{\circ} \mathrm{C}$ (Alt-C12) or $50{ }^{\circ} \mathrm{C}$ (AltC18) then cooled down to the desired temperature and equilibrated for 10 minutes. First, $1 \mathrm{rad} / \mathrm{sec}$ oscillations were applied in the 0.01 to $10 \%$ strain range. Frequency sweeps were then recorded in the linear viscoelastic regime (typically 1 $\%$ deformations) in the same isothermal conditions using $\omega=$ 100 to $0.01 \mathrm{rad} / \mathrm{sec}$ oscillations. Samples were annealed again at $90{ }^{\circ} \mathrm{C}$ (Alt-C12) or $50{ }^{\circ} \mathrm{C}$ (Alt-C18) and equilibrated as described above between measurements at two different temperatures. Additional viscosity measurements have been performed using an Anton Paar LOVIS 2000M microviscometer equipped with a $1.8 \mathrm{~mm}$ thick capillary and steel ball. Temperature was controlled at $25{ }^{\circ} \mathrm{C}$ and viscosity was measured at 13 different angles covering the $80-270 \mathrm{~s}^{-1}$ shear rate range.

Small-Angles X-ray Scattering (SAXS) and Wide Angles Xray Diffraction (WAXD): Simultaneous SAXS-WAXD measurements were conducted at DND-CAT beamline at the Advanced Photon Source in Argonne National Laboratory (Argonne, IL) operating at $17 \mathrm{keV}$ (wavelength: $\lambda=0.7293 \AA$; q-range: $0.00236-4.46 \AA^{-1}$ ). Freeze-dried samples were investigated using custom-made aluminum washers (OD: 13 $\mathrm{mm}$, ID: $4 \mathrm{~mm}$, and thickness: $1 \mathrm{~mm}$ ) covered with kapton windows on both sides. Solution for temperature-controlled experiments was investigated in $1 \mathrm{~mm}$ thick capillaries.

Small-Angles Neutrons Scattering (SANS): SANS experiments were performed on line D22 at the Institute Laue Langevin, Grenoble. Monochromatic $(\lambda=6 \AA)$ radiation was used. Samples were prepared via dissolution in toluene- $\mathrm{d}_{8}$ at $5 \mathrm{wt} \%$ concentration. The solutions and pure solvent were held in amorphous silica ("quartz") Hellma cells (optical path: 1 $\mathrm{mm}$, cell volume $=300 \mu \mathrm{L}$. The temperature was imposed by a circulating fluid in the cells' holder rack. Data collection at two sample-to-detector distances $D=1.25 \mathrm{~m}$ and $D=5.60 \mathrm{~m}$ allowed to cover the scattering wave vector range from $q=0.01$ to $0.67 \AA^{-1}$. Reduced SANS data have been corrected from incoherent scattering of the solvent and solute by introducing an adjustable background parameter in the fitting procedure. Fitting was performed using the flexible_cylinder model function provided in the SasView 4.1.2 package.

Cryo-Transmission Electron Microscopy (Cryo-TEM): The morphologies of organogels were examined using a LaB6 JEOL JEM 2100 transmission electron microscope operating at $200 \mathrm{kV}$ with a low-dose system (minimum dose system, MDS). The solutions were maintained at the $90{ }^{\circ} \mathrm{C}$ for $1 \mathrm{~h}$. Then they were spread on a quantifoil holey-carbon-coated grid (quantifoil Micro Tools) and quickly freezed by plunging the grid into liquid ethane. Images were recorded with an Ultrascan $2 \mathrm{k} \times 2 \mathrm{k}$ CCD Gatan camera. Dimensions were measured on cryo-TEM images using the ImageJ software.

\section{Synthesis of $N$-Alkylmaleimide}

$\mathrm{N}$-octyl maleimide (C8MI), $\mathrm{N}$-dodecyl maleimide (C12MI) and $N$-octadecyl maleimide (C18MI) were synthesized according to the literature. ${ }^{10}$

\section{Polymer Synthesis}

Polymerization was carried out by syringe technique under dry argon in baked glass tubes equipped with three-way stopped cock. Typical procedures for synthesis of copolymer with tBOS and C12MI via free or living radical polymerization were as follows.

Synthesis of Alt-C12 via Free Radical Polymerization: To a Schlenk tube, C12MI (2.654 g, $1.0 \times 10-2 \mathrm{~mol})$ and AIBN (32.84 mg, $2.0 \times 10-4 \mathrm{~mol}$ ) was added and degassed by vacuum pump at $-78{ }^{\circ} \mathrm{C}$. Then, tBOS $(1.88 \mathrm{~mL}, 1.0 \times 10-2 \mathrm{~mol})$, tetralin $(0.2 \mathrm{~mL})$ and toluene $(7.92 \mathrm{~mL})$ were added under dry argon flow (concentration: $\mathrm{tBOS} / \mathrm{C} 12 \mathrm{MI} / \mathrm{AIBN}=1000 / 1000 / 20 \mathrm{mM}$ ). Immediately after mixing, the tube was placed in oil bath at 60 ${ }^{\circ} \mathrm{C}$ for $1 \mathrm{~h}$ and the copolymerization was terminated by bubbling with air. Monomer conversion was determined by ${ }^{1} \mathrm{H}$ NMR from the integrated peak area of the olefinic protons of the monomers with tetralin as an internal standard (conversion: tBOS/C12MI $=98 / 99 \%$ ). The solution was diluted by THF (total volume of the diluted solution was about $60 \mathrm{~mL}$ ) and the solution was added in dropwise in $2 \mathrm{~L}$ of methanol with stirring. The precipitate was filtered and washed by methanol. The filtered solid was dissolved in 1,4-dioxane and the solution was freeze-dried to yield the alternating copolymer [poly(tBOS-alt-C12MI)] as white solid (4.16 g): $M_{\mathrm{n}}=91,900$, $M_{\mathrm{w}} / M_{\mathrm{n}}=6.45$ (from THF GPC, after purification). The composition ratio of the purified copolymer was determined by ${ }^{1} \mathrm{H}$ NMR from the integrated peak area of the aromatic protons of tBOS and ethylene protons neighboring to nitrogen atom of maleimide (tBOS/C12MI = 49/51). In a flask, $4.0 \mathrm{~g}$ of poly(tBOS-alt-C12MI) was dissolved in $100 \mathrm{~mL}$ of THF. Then, $13.3 \mathrm{~mL}$ of $37 \% \mathrm{HCl}$ aq. was added slowly in the solution with stirring. The solution was heated at reflux with a condenser and stirring for $20 \mathrm{~h}$. After cooling, the solution was added in dropwise in $3 \mathrm{~L}$ of water with stirring. The precipitate was filtered and washed by pure water for several times until the $\mathrm{pH}$ of the filtered water became 7 . Then, the filtered solid was dissolved in 1,4-dioxane and the solution was freeze-dried to yield the poly(4-vinylphenol-alt-C12MI) (Alt-C12) as white solid (3.41 g): $M_{\mathrm{n}}=88,000, M_{\mathrm{w}} / M_{\mathrm{n}}=6.61$ (from THF GPC). The progress of deprotection was confirmed by ${ }^{1} \mathrm{H}$ NMR. 
Synthesis of Alt-C12 via RAFT polymerization: To a Schlenk tube, C12MI (1.327 g, $5.0 \times 10-3 \mathrm{~mol})$ and AIBN (0.1 $\mathrm{mL}$ of $0.82 \mathrm{wt} \%$ in toluene, $\left.5.0 \times 10^{-6} \mathrm{~mol}\right)$ was added and degassed by vacuum pump at $-78{ }^{\circ} \mathrm{C}$. Then, tBOS $(0.941 \mathrm{~mL}$, $\left.5.0 \times 10^{-3} \mathrm{~mol}\right)$, tetralin $(0.1 \mathrm{~mL})$, toluene $(3.68 \mathrm{~mL})$ and CTA $\left(0.277 \mathrm{~mL}\right.$ of $90.001 \mathrm{mM}$ in toluene, $\left.2.5 \times 10^{-5} \mathrm{~mol}\right)$ were added (concentration: tBOS/C12MI/CTA/AIBN $=1000 / 1000 / 5 / 1$ $\mathrm{mM}$ ) under dry argon flow. Immediately after mixing, the tube was placed in oil bath at $60^{\circ} \mathrm{C}$ for $4 \mathrm{~h}$ and the copolymerization was terminated by bubbling with air. Monomer conversion was determined by ${ }^{1} \mathrm{H}$ NMR from the integrated peak area of the olefinic protons of the monomers with tetralin as an internal standard (conversion: $\mathrm{tBOS} / \mathrm{C} 12 \mathrm{MI}=95 / 97 \%$ ). Then, the solution was diluted by THF and the solution was added in dropwise in $1 \mathrm{~L}$ of methanol with stirring. The precipitate was filtered and washed by methanol. The filtered solid was dissolved in 1,4-dioxane and the solution was freeze-dried to yield the alternating copolymer [poly(tBOS-alt-C12MI) (n = 190)] as white solid (2.25 g): $M_{\mathrm{n}}=57,100, M_{\mathrm{w}} / M_{\mathrm{n}}=1.28$ (from THF GPC, after purification), composition ratio tBOS/C12MI $=49 / 51$ (from ${ }^{1} \mathrm{H}$ NMR, after purification). In a flask, $1.1 \mathrm{~g}$ of poly(tBOS-alt-C12MI) was dissolved in $41 \mathrm{~mL}$ of THF. Then, $8 \mathrm{~mL}$ of $37 \% \mathrm{HCl}$ aq. was added slowly in the solution with stirring. The solution was heated at reflux with a condenser and stirring for $20 \mathrm{~h}$. After cooling, the solution was added in dropwise in $1 \mathrm{~L}$ of water with stirring. The precipitate was filtered and washed by pure water for several times until the $\mathrm{pH}$ of the filtered water became 7 . Then, the filtered solid was dissolved by 1,4-dioxane and the solution was freeze-dried to yield the poly(4-vinylphenol-alt-C12MI) as white solid (730 $\mathrm{mg}$ ): $M_{\mathrm{n}}=54,600, M_{\mathrm{w}} / M_{\mathrm{n}}=1.29$ (from THF GPC). The progress of deprotection was confirmed by ${ }^{1} \mathrm{H}$ NMR and FTIR.

\section{Preparation of Organogel}

In a vial, the freeze-dried Alt-C12 $(100 \mathrm{mg})$ was dissolved in aromatic solvent $(2 \mathrm{~mL})$ at $80 \sim 90{ }^{\circ} \mathrm{C}$ by heat gun $(5 \mathrm{wt} \%$ solution). Then, the solution was cooled to room temperature to form turbid gel.

\section{Results and discussion}

\section{Syntheses and Characterizations of Alternating Copolymers}

Free radical copolymerizations of tBOS with $\mathrm{N}$ alkylmaleimide (alkyl: $-\mathrm{C}_{2} \mathrm{H}_{5},-\mathrm{C}_{8} \mathrm{H}_{17},-\mathrm{C}_{12} \mathrm{H}_{25},-\mathrm{C}_{18} \mathrm{H}_{37}$ ) were conducted with 2,2'-azobisisobutyronitrile (AIBN) as the initiator. The resultant copolymers were treated with $\mathrm{HCl}$ for deprotection of the repeating tert-butoxy groups giving rise to alternating copolymers of vinyl phenol and $\mathrm{N}$-alkylmaleimides (Figure 3a). Both of the comonomers were consumed at same rate and the conversions reached $>90 \%$ in several hours (Table $\mathrm{S} 1$ in supporting information). Figure $3 \mathrm{~b}$ summarizes data of $M_{\mathrm{n}}, M_{\mathrm{w}} / M_{\mathrm{n}}$, and composition ratio (x/y) of the resultant copolymers after deprotection (Alt-C2, -C8, -C12, -C18) (C12MI) (SEC curves of alternating copolymer are shown in Figure S1). Molecular weights of all the copolymers are enough high and composition ratios were almost 1:1. Figure $3 \mathrm{c}$

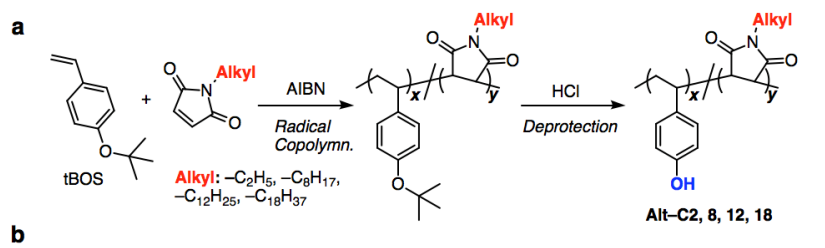

b

\begin{tabular}{|c|c|c|c|}
\hline $\begin{array}{l}\text { Abbrev. of } \\
\text { Alternating } \\
\text { Copolymer }\end{array}$ & Alkyl & $\begin{array}{c}M_{n}\left(M_{w} / M_{n}\right) \\
\text { SEC, PS Calib. }\end{array}$ & $\begin{array}{c}\text { Composition Ratio } \\
\boldsymbol{x} / \boldsymbol{y},{ }^{1}{ }^{H} \text { NMR }\end{array}$ \\
\hline Alt-C2 & $\xi_{\left(-\mathrm{C}_{2} \mathrm{H}_{5}\right)}$ & $49,700(3.28)$ & $50 / 50$ \\
\hline Alt-C8 & $\left\{\left(-\mathrm{C}_{8} \mathrm{H}_{17}\right)\right.$ & $121,300(2.82)$ & $49 / 51$ \\
\hline Alt-C12 & $\left(-\mathrm{C}_{12} \mathrm{H}_{25}\right)$ & $88,100(6.61)$ & $49 / 51$ \\
\hline Alt-C18 & $\left(-\mathrm{C}_{18} \mathrm{H}_{37}\right)$ & $209,600(2.41)$ & $49 / 51$ \\
\hline
\end{tabular}

c

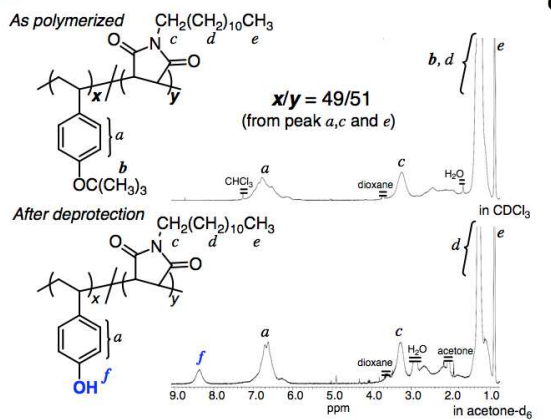

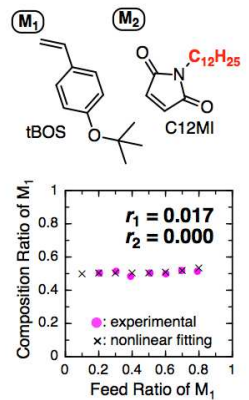

Fig. 3 (a) Synthetic scheme of alternating copolymers with 4-vinylphenol and $\mathrm{N}$ alkylmaleimide: $[\mathrm{tBOS}]_{0} /[\mathrm{N} \text {-alkylmaleimide }]_{0} /[\mathrm{AIBN}]_{0}=1000 / 1000 / 20 \mathrm{mM}$ in toluene at $60{ }^{\circ} \mathrm{C}$, (b) table of molecular weight and composition of copolymers after deprotection reaction, (c) ${ }^{1} \mathrm{H}$ NMR spectra of the copolymer with tBOS and $\mathrm{C} 12 \mathrm{MI}$ (upper) and the copolymer after deprotection reaction (lower) and (d) monomer reactivity ratios of tBOS $\left(\mathrm{M}_{1}\right)$ and $\mathrm{C} 12 \mathrm{MI}\left(\mathrm{M}_{2}\right)$ calculated from non-linear method.

shows ${ }^{1} \mathrm{H}$ NMR spectra before and after deprotection of the copolymer with $\mathrm{N}$-dodecylmaleimide (C12MI) $\left({ }^{1} \mathrm{H} \quad \mathrm{NMR}\right.$ spectra for another copolymer are shown in Figure S3-S5). From the spectrum before deprotection, the composition ratio $(\mathrm{x} / \mathrm{y})$ was determined by using three peaks $(a, c$ and $e$ ) to determine $x / y=49 / 51$. The deprotection of tert-butoxy groups in the copolymer was done under reflux of the THF solution in the presence of $\mathrm{HCl}$. A peak $b$ from tert-butoxy groups clearly disappeared and instead a new peak derived from the hydroxy proton $(f)$ appeared, indicating quantitative deprotection. The deprotection reaction was also confirmed by FT-IR (Figure S2). The radical copolymerizations were performed with various injection ratios of the comonomer pair tBOS and C12MI to determine reactivity ratios by non-linear fitting method. The values were almost zero $\left[r_{1}=0.017, r_{2}=0.000\left(\mathrm{M}_{1}=\mathrm{tBOS}, \mathrm{M}_{2}\right.\right.$ $=\mathrm{C} 12 \mathrm{MI})$; Figure $3 \mathrm{~d}]$. Thus selective cross propagation likely took place to give highly alternating copolymer under condition of 1:1 injection ratio. The alternating sequence was also supported by MALDI-TOF-MS for the copolymer sample synthesized by reversible addition fragmentation transfer (RAFT) polymerization ${ }^{11}$ (Figure S6).

\section{Solubility of the Copolymers}

Solubilities of the vinyl phenol-alkyl maleimide alternating copolymers (Alt-C2, -C8, -C12, -C18) in various solvents were 
investigated ( $1 \mathrm{wt} \%$ at $25{ }^{\circ} \mathrm{C}$, Table 1$)$. The copolymers showed almost same trend in solubility: soluble in THF, ethyl acetate, acetone and DMF, insoluble in hexane and methanol. As for chloroform, toluene, DMSO and $\mathrm{NaOH}$ aq., the solubilities depend on the alkyl chain. Thus Alt-C8, Alt-C12 and Alt-C18 are all totally insoluble in water, whereas Alt-C2 is soluble at high $\mathrm{pH}$ and reversely Alt-C8, Alt-C12 and Alt-C18 are all soluble in chloroform whereas Alt-C2 is not. Thus by constitution, the alternated copolymers present an amphiphilic structure: on one end, the lipophilic side chains have more affinity for weakly polar solvents whereas lipophobic phenol units show better affinity for water and polar solvents thus featuring an alternating lipophilic/lipophobic polyamphiphile structure whose lipophilic/lipophobic balance may be tuned by the length of the alkyl side chains.

Interestingly, when toluene was added to the two alternating copolymers carrying long alkyl chains (Alt-C12 and Alt-C18) at $25{ }^{\circ} \mathrm{C}$, these white powder samples swelled to jelly. However, when they were heated to $80{ }^{\circ} \mathrm{C}$, the polymers turned into soluble giving fluid solutions. The homogeneous and transparent solution of Alt-C18 in toluene (1wt\%) that was prepared at $80{ }^{\circ} \mathrm{C}$ turned into viscous via the cooling process to ambient temperature while remaining optically transparent. On the other hand, in the case with Alt-C12, a more pronounced

\begin{tabular}{ccccc}
\hline Table 1 Solubility of the Copolymers at $25{ }^{\circ} \mathrm{C}^{a}$ & & \\
\hline Solvent & Alt-C2 & Alt-C8 & Alt-C12 & Alt-C18 \\
\hline Hexane & Insol. & Insol. & Insol. & Insol. $^{b}$ \\
\hline Toluene & Insol. & Insol. & Swollen $^{b}$ & Swollen $^{b}$ \\
\hline THF & Sol. & Sol. & Sol. & Sol. \\
\hline Chloroform & Insol. & Sol. & Sol. & Sol. \\
\hline $\begin{array}{c}\text { Ethyl } \\
\text { Acetate }\end{array}$ & Sol. & Sol. & Sol. & Sol. \\
\hline Acetone & Sol. & Sol. & Sol. & Part-Sol. \\
\hline Methanol & Insol. & Insol. ${ }^{c}$ & Insol. & Insol. \\
\hline DMF & Sol. & Sol. & Sol. & Part-Sol. \\
\hline DMSO & Sol. & Insol. ${ }^{c}$ & Part-Sol. & Insol. \\
\hline Water & Insol. & Insol. & Part-Sol. & Insol. \\
\hline NaOH aq. & Sol. & Insol. & Insol. & Insol. \\
\hline
\end{tabular}

Sol.: Soluble, Insol.: Insoluble, Part-Sol.: Partially Soluble, Swollen: Insoluble and Swollen, ${ }^{a}$ Polymer Concentration: $1 \mathrm{wt} \%,{ }^{b}$ Soluble at $80{ }^{\circ} \mathrm{C},{ }^{c}$ Soluble at $60^{\circ} \mathrm{C}$. a

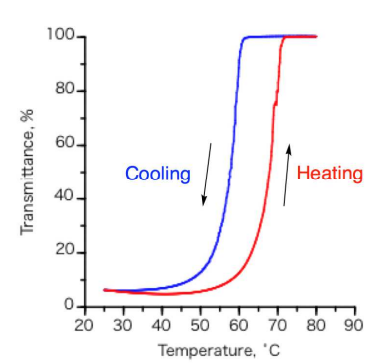

b

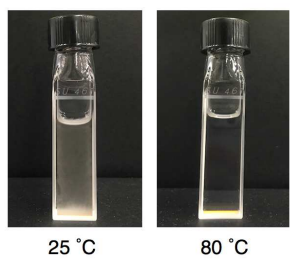

Fig 4. (a) Turbidity measurement of $1 \mathrm{wt} \%$ Alt-C12 solution in toluene: heating speed $=0.5^{\circ} \mathrm{C} / \mathrm{min}$, wavelength $\lambda=670 \mathrm{~nm}$, (b) pictures of the $1 \mathrm{wt} \%$ Alt-C12 solution in toluene at $25^{\circ} \mathrm{C}$ and $80^{\circ} \mathrm{C}$. turbidity was generated through the cooling process. The thermal response behavior of Alt-C12 was further studied with turbidity measurements. Figure 4 shows the turbidity measurement (wavelength $\lambda=670 \mathrm{~nm}$ ) on the cooling from 80 ${ }^{\circ} \mathrm{C}$ to $25{ }^{\circ} \mathrm{C}$ and the reheating to $80{ }^{\circ} \mathrm{C}$. The solution started to become turbid around $60{ }^{\circ} \mathrm{C}$ on the cooling process and the transmittance was almost lost below around $50{ }^{\circ} \mathrm{C}$. The thermal response was reversible with a few degrees hysteresis and similar transmittance curve was obtained on the heating.

\section{Physical Gel}

As described above, the long alkyl chain-pendant alternating copolymers (Alt-C12 and Alt-C18) were found to show unique thermal response behaviors in diluted toluene solution $(1 \mathrm{wt} \%)$. We then prepared more concentrated solutions in toluene $(5 \mathrm{wt} \%)$ to study the thermal response behaviors. Even the concentrated solutions of both copolymers became soluble at $80{ }^{\circ} \mathrm{C}$ giving homogeneous and fluid solutions but they turned into viscous via cooling process. Finally the flowability was completely lost to yield gels at ambient temperature. The gels were again soluble at $80{ }^{\circ} \mathrm{C}$ and gelated again via the cooling process indicating they are thermally responsive physical gels. Interestingly, these copolymers gelated in other aromatic solvents, such as anisole, p-cymene, cumene, 1,2,4-trichlorobenzene, nitrobenzene (Figure 5). The turbidity and hardness of the resultant organogels depended on the solvent as well as the alkyl substituent, which is likely due to differences in their structures and morphologies. For instance, both of the copolymers gave obviously harder gels with 1,2,4-trichlorobenzene than other aromatic solvents, and Alt-C18 did not give gel in nitrobenzene specifically. Detailed study in effects of aromatic solvent on

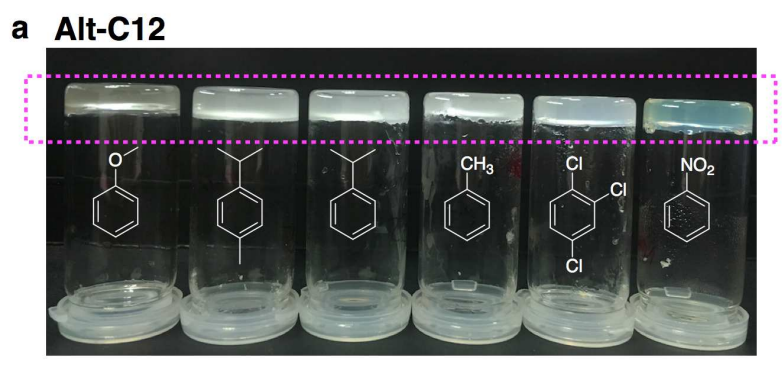

\section{b Alt-C18}

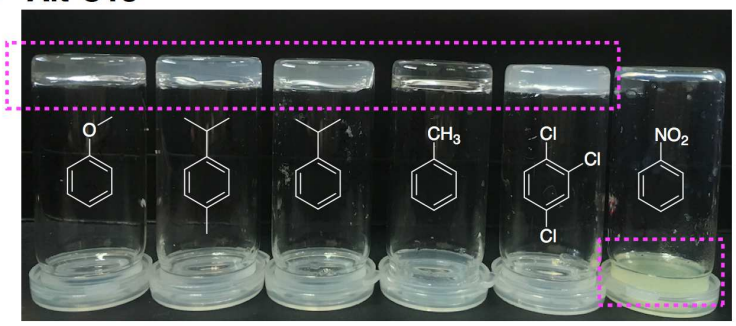

Fig 5. Appearances of $5 w t \%$ solutions of (a) Alt-C12 and (b) Alt-C18 in various aromatic solvents at ambient temperature $\left(\sim 25^{\circ} \mathrm{C}\right)$ after cooling from $80^{\circ} \mathrm{C}$. The sample tubes were turned upside down for demonstration of gel formation (from left to right: anisole, $p$-cymene, cumene, toluene, 1,2,4trichlorobenzene, nitrobenzene solvents). 
the gelation behaviors is now under investigation.

\section{Detailed Study on Physical Gels in Toluene}

To investigate the gelation mechanism in toluene, the solution of Alt-C12 in toluene-d $\mathrm{d}_{8}(5 \mathrm{wt} \%)$ was prepared at $80{ }^{\circ} \mathrm{C}$ for variable temperature ${ }^{1} \mathrm{H}$ NMR measurements (Figure 6). In the spectrum measured at $25{ }^{\circ} \mathrm{C}$, few peaks derived from the copolymer were observed: a broad and very small peak 1-3 ppm that is likely from alkyl pendant and back bone protons; no peak from aromatic protons of vinyl phenol units around $7 \mathrm{pm}$. When it was measured at $60{ }^{\circ} \mathrm{C}$, the peaks from the $\mathrm{C}_{12}$ alkyl pendant of the maleimide unit $(d, e)$ became larger, and further heating up to $80{ }^{\circ} \mathrm{C}$ made the intensities stronger. The vinyl phenol peak from aromatic protons of vinyl phenol units was observed only after the temperature was heated to $80{ }^{\circ} \mathrm{C}$. The similar trend was obtained with Alt-C18 (Figure S7) but with overall better resolved peaks, meaning overall higher mobility with this longer chain. Thus for instance, the characteristic signals of the $\mathrm{C}_{18}$ pendant $(d, e)$ are well defined at $25{ }^{\circ} \mathrm{C}$ and that of the vinyl phenol $(a)$ is already detected at $60{ }^{\circ} \mathrm{C}$.

From the variable temperature ${ }^{1} \mathrm{H}$ NMR measurements, it is evident that the phenol groups and the hydrocarbon side chains become mobile in two different temperature ranges hence indicating that these fragments are segregated in the gel structure. Hydrogen bonding between phenol units is supposed to play a part in the gelation behavior, in competition with solubility and mobility brought by alkyl chains. The hydrogen bonding interaction works well at low temperature but it becomes weaker on heating, which corresponds to the thermal response behavior observed. Indeed, the alternating copolymer of C12MI with styrene instead of vinyl phenol was soluble in toluene and no gelation occurred (Figure 7a). To further confirm the hydrogen bond-driven gelation, a tiny drop of

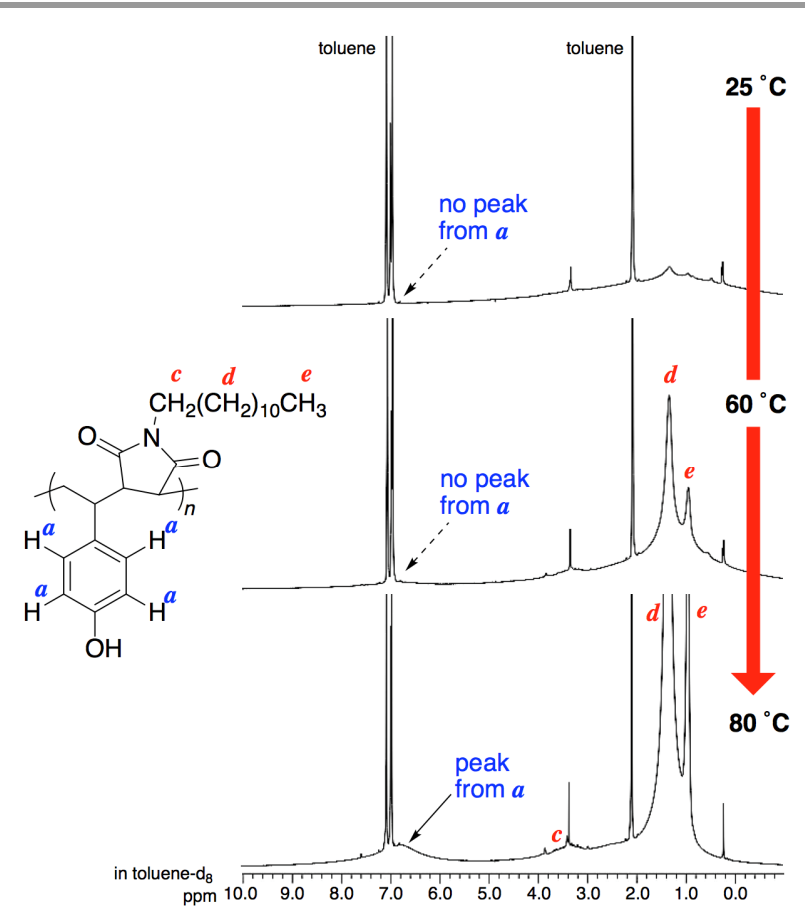

Fig 6. ${ }^{1} \mathrm{H}$ NMR spectra of $5 \mathrm{wt} \%$ Alt-C12 gel in toluene- $\mathrm{d}_{8}$ at $25{ }^{\circ} \mathrm{C}, 60^{\circ} \mathrm{C}$ and $80^{\circ} \mathrm{C}$.
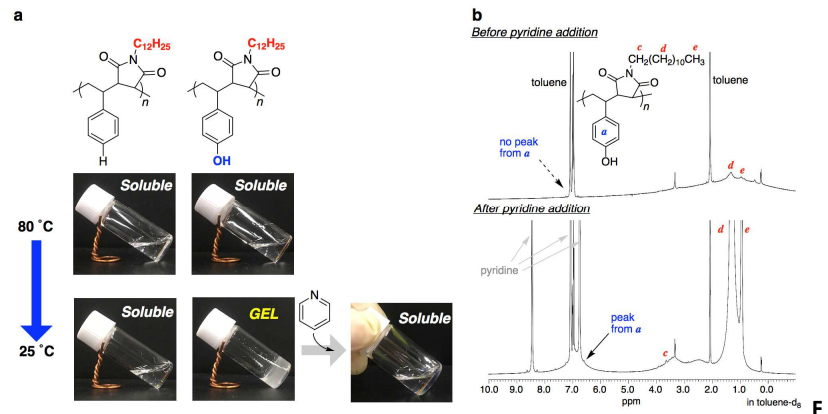

ig 7. (a) Relation between polymer structures and solubilities and (b) ${ }^{1} \mathrm{H}$ NMR spectra of $5 \mathrm{wt} \%$ Alt-C12 gel in toluene- $\mathrm{d}_{8}$ (upper) and after addition of pyridine (lower): [phenol unit in gel] = [added pyridine] .

pyridine was added into the gel of Alt-C12 in toluene. Consequently, the gel turned into soluble to give a fluid solution. Interestingly, the transition is sensitive to the pyridine amount: for example, addition of half molar quantity of pyridine (with respect to the amount of phenol groups in the alternating copolymer) made the gel softer, the perfect solubilization took place once a stoichiometric molar amount of pyridine was added but the viscosity was still beyond the range of the falling ball viscometer. After addition of two equivalents of pyridine, the measured viscosity was as low as $8.4 \mathrm{mPa} \cdot \mathrm{s}$, i.e. only ten times higher than the one of pure toluene and comparable to the viscosity of the THF solution (Table S3). The solubilization by the pyridine addition was also supported by ${ }^{1} \mathrm{H}$ NMR (Figure 7b): some copolymer peaks were clearly observed even at $25{ }^{\circ} \mathrm{C}$ after addition of a stoichiometric molar amount of pyridine, similar to that at $80{ }^{\circ} \mathrm{C}$. These experiment nicely confirm the role of hydrogen bonding in gelation.

\section{Control of Molecular Weight for Study on Molecular Weight Dependence}

To examine effects of molecular weight on gelation, the alternating copolymers of vinyl phenol with C12MI having various molecular weights were synthesized via RAFT polymerization. The 1:1 copolymerization of tBOS and C12MI was conducted with 4-cyano-4-[(dodecylsulfanylthiocarbonyl) sulfanyl]pentanol as a chain transfer agent (CTA) in conjunction with AIBN as an initiator. The molecular weight was controlled by changing the ratio of the comonomers to CTA: [each comonomer $]_{0} /[\mathrm{CTA}]_{0}=1000 / 5,1000 / 10,500 / 10$, $300 / 10$, and 100/10 mM (Figure 8). The two comonomers were consumed at same rate under every condition, and the conversions reached to over $90 \%$ (Table S2). The resultant 5 copolymer samples underwent $\mathrm{HCl}$ treatment for the tertbutoxy group deprotection, similar to the copolymers synthesized via free radical polymerization. The quantitative deprotection was confirmed by ${ }^{1} \mathrm{H}$ NMR and the molecular weights were characterized by GPC. The molecular weights of the copolymers showed a clear dependence on the ratio, and the molecular weight distributions were narrow enough $\left(M_{\mathrm{w}} / M_{\mathrm{n}}<\right.$ 1.30, Figure 8a). For lower molecular weight copolymers, the number-averaged polymerization degree for the two units $(n)$ that was characterized by ${ }^{1} \mathrm{H}$ NMR well agreed with the value calculated from the injection ratio and conversion. The ${ }^{1} \mathrm{H}$ 
NMR characterization was not accessible to the higher molecular weight polymers, so calculated values for $n$ were adopted for all the 5 samples in this work $(n=10,29,45,95$, and 190).

Solubilities and gelation behaviors in toluene were studied with the 5 copolymers of different molecular weights. Figure $8 \mathrm{~b}$ shows dependence of gelation on polymerization degree and concentration. For example, the shortest copolymer $(n=10)$ never gelated at any concentration, whereas the longest one ( $n$ $=190$ ) did at lower concentration (i.e., 3wt\%). As shown in Figure $8 \mathrm{~b}$, the critical gelation concentration (CGC) obviously depends on the molecular weight of the copolymer.

The thermal response behaviors were also studied for the $1 w t \%$ solutions in toluene. The lower molecular weight copolymers $(n=10,29)$ were soluble in toluene even at lower temperature. On the other hand, the solutions of the higher molecular weight samples ( $n=45,95$ and 190) became cloudy at lower temperature. Figure $8 \mathrm{c}$ shows turbidity measurement of the $1 \mathrm{wt} \%$ solution in toluene. The transition temperature depended on the molecular weight: it increased as the molecular weight was higher.

The alkyl group of maleimide is basically soluble in a hydrophobic solvent (i.e.,toluene) due to the high hydrophobicity. Thus the periodically embedded hydrophobic maleimide units would be helpful for expanding chain due to the high affinity for solvent as well as the rigidity, and the phenol units dynamically interact with each other via hydrogen bonding to give a non-covalent network. The alternating sequence therefore contributes to the balance of the two effects.

a

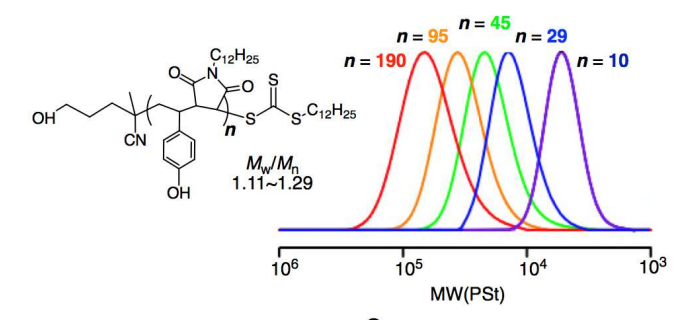

b

c
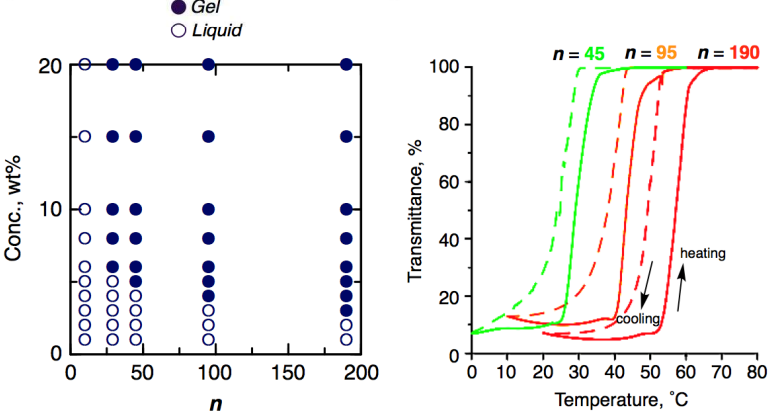

Fig 8. (a) GPC curves of copolymers synthesized by RAFT polymerization and deprotection reaction: $[\mathrm{tBOS}]_{0} /[\mathrm{C} 12 \mathrm{MI}]_{0} /[\mathrm{CTA}]_{0} /[\mathrm{AIBN}]_{0}=1000 / 1000 / 5 / 1$ $\mathrm{mM}(\boldsymbol{n}=190), 1000 / 1000 / 10 / 1 \mathrm{mM}(\boldsymbol{n}=95), 500 / 500 / 10 / 1 \mathrm{mM}(\boldsymbol{n}=45)$, $300 / 300 / 10 / 1 \mathrm{mM}(\boldsymbol{n}=29), 100 / 100 / 10 / 1 \mathrm{mM}(\boldsymbol{n}=10)$ in toluene at $60{ }^{\circ} \mathrm{C}$, (b) polymerization degree $(\boldsymbol{n})$-concentration plot: (filled circle: gel, open circle: liquid) and (c) turbidity measurements for $1 \mathrm{wt} \%$ copolymer solutions in toluene $(n=45,95,190)$ (heating speed $=0.5^{\circ} \mathrm{C} / \mathrm{min}$, wavelength $\lambda=670$ $\mathrm{nm})$. a

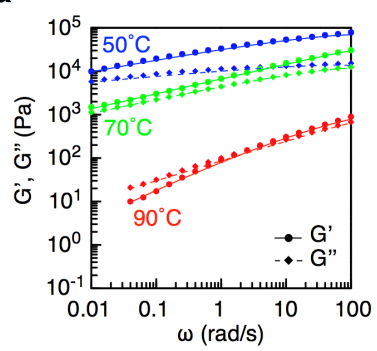

b

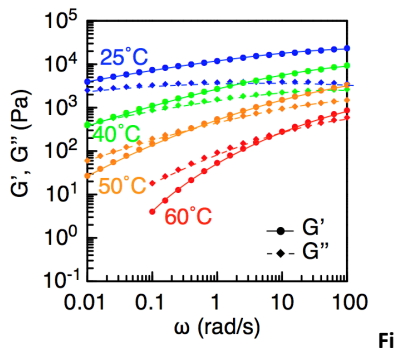

Fig 9. Rheology of organogels $10 w t \%$ in 1,2,4,-trichlorobenzene $(\gamma=1)$ : (a) Alt-C12 and (b) Alt-C18.

For inducing self-assembly or gelation, a certain number of phenol groups in one alternating copolymer chain should be necessary, as demonstrated by the dependence of gelation on the polymerization degree.

\section{Rheology Measurement of the Gel}

Temperature-variable rheology was investigated with the physical gel samples of the alternating copolymers. For themeasurement, 1,2,4-trichlorobenzene was used as the solvent due to the higher boiling point $\left(213{ }^{\circ} \mathrm{C}\right)$ to avoid evaporation during measurement. The $10 \mathrm{wt} \%$ solutions of AltC12 or Alt-C18 in 1,2,4-trichlorobenzene were first prepared at $90{ }^{\circ} \mathrm{C}$ and they were converted into the physical gels by cooling to ambient temperature. Here, $5 \mathrm{wt} \%$ gels were not suitable for the measurement of rheology because of big syneresis at low temperature. Figure 9 shows isothermal $\omega$-sweeps for the samples of Alt-C12 and Alt-C18 at different temperatures. At $60{ }^{\circ} \mathrm{C}$, Alt-C18 showed the response of a viscoelastic liquid: the relaxation time, estimated by the angular frequency of the $G^{\prime}=G^{\prime \prime}$ cross-over point, was of about $0.1 \mathrm{~s}$; the terminal regime $\left(G^{\prime} \approx \omega^{2} ; G^{\prime \prime} \approx \omega\right)$ was evident in the low frequency region. At lower temperatures, the crossover point was shifted to significantly longer relaxation times (about $3 \mathrm{~s}$ at $50{ }^{\circ} \mathrm{C}, 10 \mathrm{~s}$ at $40{ }^{\circ} \mathrm{C}$ and outside the measurable range at $25^{\circ} \mathrm{C}$ ), whereas the terminal regime disappeared and the absolute values of the elastic modulus increased $(100 \mathrm{kPa}$ at $1 \mathrm{~Hz})$ thus giving the image of a rather stiff transient network or entangled system with very long relaxation time at room temperature. For AltC12, the general behavior was comparable but the terminal regime was hardly visible at $90{ }^{\circ} \mathrm{C}$. The relaxation time was about $2 \mathrm{~s}$ at $90{ }^{\circ} \mathrm{C}$ and already outside the measurable range at $70{ }^{\circ} \mathrm{C}$. Absolute values of moduli were higher (about $300 \mathrm{kPa}$ at $1 \mathrm{~Hz}$ ) fully consistent with the lower mobility found by ${ }^{1} \mathrm{H}$ NMR in the Alt-C12 organogel compared with Alt-C18 organogel.

\section{Structure Analysis in the Bulk and Organogel State}

Before structure analysis of the physical gels, the structures of Alt-C12 and Alt-C18 at solid state were analysed by DSC and wide angle X-ray diffraction (WAXD) because these characterization would be helpful for understanding the gel structure. Figure S8 shows DSC thermograms of the bulk samples with Alt-C12 and Alt-C18 recorded at a heating rate of $10^{\circ} \mathrm{C} / \mathrm{min}$. For Alt-C18, two distinct endothermic signals were 
detected around $150{ }^{\circ} \mathrm{C}\left(\Delta H_{\mathrm{m}}=0.8 \mathrm{~J} / \mathrm{g}\right)$ and $200{ }^{\circ} \mathrm{C}\left(\Delta H_{\mathrm{m}}=4.6\right.$ $\mathrm{J} / \mathrm{g})$. On the other hand, a broad endothermic signal $\left(\Delta H_{\mathrm{m}} \approx 6\right.$ $\mathrm{J} / \mathrm{g}$ ) was observed between 150 and $200{ }^{\circ} \mathrm{C}$ with Alt-C12. Such values should be compared to the melting enthalpy of reference materials featuring the same type of crystallizable fragments. Thus for instance, paraffin wax has a melting enthalpy of about $200 \mathrm{~J} / \mathrm{g},{ }^{12}$ and recently synthesized $\mathrm{p}$ (Sty-alt-MAnh) derivatives with $\mathrm{C}_{22}$ alkyl side chains ${ }^{8}$ showed a melting enthalpy of about $50 \mathrm{~J} / \mathrm{g}$ hence indicating by comparison a very low level of crystallinity in our compounds.

WAXD patterns of bulk Alt-C12 and Alt-C18 are presented in Figure S10. In Figure 10ab, the same data is plotted as a function of $q=4 \pi(\sin \theta) / \lambda$. In the wide $q$ region, a broad diffraction peak was detected with a maximum at the same position, $q=1.38 \AA^{-1}\left(2 \theta=9.1^{\circ}\right)$ for both samples, which corresponds to an average spacing of $2 \pi / q=4.6 \AA$. Such a signal is ubiquitous in molten polymers and amphiphiles and corresponds to the amorphous packing of hydrocarbon chains. ${ }^{13}$ At lower $q$ values, another signal was detected for both compounds but its position depends on the length of the alkyl side chains: the maximum arose at $q=0.248 \AA^{-1}\left(2 \theta=1.63^{\circ}\right)$ for Alt-C12 and at $q=0.192 \AA^{-1}\left(2 \theta=1.31^{\circ}\right)$ for Alt-C18. This corresponds to an average spacing of $2 \pi / q=25 \AA$ for Alt$\mathbf{C 1 2}$ and $2 \pi / q=33 \AA$ for Alt-C18. In Figure S9, we report calculated dimensions of the repeat unit with alkyl side chains in the fully extended conformation. The maximum possible distance between terminal $\mathrm{CH}_{3}$ and $\mathrm{OH}$ groups is $l=22 \AA$ for Alt-C12 and $l=29 \AA$ for Alt-C18. To account for such distances, intermediate between once and twice the molecular dimensions, and considering the analogy between the repeating unit and an amphiphile, we propose a packing of inverse micelle-like cylinders composed of hydrogen bonded phenol
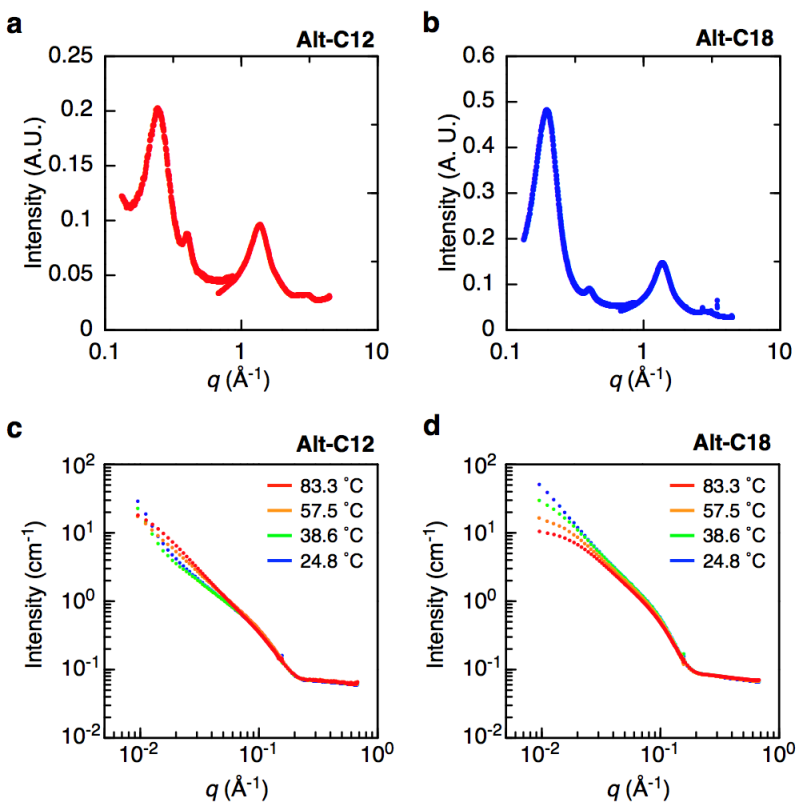

Fig 10. Wide angle $X$-ray diffraction patterns of freeze dried bulk Alt-C12 (a) and Alt-C18 (b) (The peak arising at $q=0.4 \AA^{-1}\left(2 \theta=2.7^{\circ}\right)$ is due to Kapton windows.) and SANS profiles of 5wt\% Alt-C12 (c) and Alt-C18 (d) in toluene$\mathrm{d}_{8}$ at various temperatures.
Table 2 Fitting Parameters from Modeling of SANS Data Recorded at Various Temperature: $5 w t \%$ Solutions in Toluene- $d_{8}$

\begin{tabular}{lrrrrr}
\hline Sample & $\begin{array}{c}\text { Temp. } \\
\left({ }^{\circ} \mathrm{C}\right)\end{array}$ & $\begin{array}{c}\text { Av. } \\
\text { radius } \\
(\AA)\end{array}$ & $\begin{array}{c}\text { Kuhn } \\
\text { length } \\
(\AA)\end{array}$ & $\begin{array}{c}\text { Contour } \\
\text { length } \\
(\AA)\end{array}$ & $\begin{array}{c}\text { Back } \\
\text { ground } \\
\left(\mathrm{cm}^{-1}\right)\end{array}$ \\
\hline Alt-C12 & 83.3 & 14.7 & 44.3 & 2250 & 0.0661 \\
\cline { 2 - 6 } & 57.5 & 15.3 & 79.4 & 1470 & 0.0663 \\
\cline { 2 - 6 } & 38.6 & 15.0 & 135.0 & 53800 & 0.0653 \\
\hline \multirow{2}{*}{ Alt-C18 } & 24.8 & 15.0 & 99.4 & 122000 & 0.0640 \\
\cline { 2 - 6 } & 83.3 & 17.2 & 77.0 & 447 & 0.0755 \\
\cline { 2 - 6 } & 57.5 & 17.4 & 73.4 & 688 & 0.0741 \\
\hline & 38.6 & 17.6 & 65.3 & 1510 & 0.0743 \\
\hline & 24.8 & 17.9 & 66.9 & 12300 & 0.0734 \\
\hline
\end{tabular}

groups in the core surrounded by radically distributed alkyl chains. ${ }^{14}$ Starting from above calculated distances, the local order was considered to be close to a hexagonal packing ${ }^{15}$ giving rise to a Bragg spacing of $2 l / \sqrt{ } 3=25.4 \AA$ for Alt-C12 and $2 l / \sqrt{ } 3=33.5 \AA$ for Alt-C18, which matches the measured values.

In both compounds, the low- $q$ Bragg peak appears to be rather broad (Figure S10), showing a full width at half maximum of $\Delta 2 \theta \approx 0.6^{\circ}$ (Alt-C12) and $\Delta 2 \theta \approx 0.5^{\circ}$ (Alt-C18). These values are evidently much larger than the experimental resolution $\left(\Delta 2 \theta\right.$ of integrated bins $\left.\approx 0.01^{\circ}\right)$ and the crystal size $L$ determined through the Scherrer equation ${ }^{16} L=\lambda /[(\Delta 2 \theta) \cos \theta]$ is of about $70-90 \AA$, thus confirming the picture of a very defective semi-crystalline arrangement.

After swelling with a solvent, the low- $q$ Bragg peak disappears for both compounds. The SANS data of Alt-C12 and Alt-C18 in toluene- $\mathrm{d}_{8}$ are shown for several temperatures in Figure 10cd. For both compounds, the logarithmic plot of data in the 0.01 to $1 \AA^{-1}$ region reveals several slopes. Whilst the high- $q$ region is very similar for all spectra, we observe an upturn of scattered intensity at low $q$ when temperature is decreased, consistent with the growth of large percolating objects and indeed it is in the same temperature range (from 90 to $25{ }^{\circ} \mathrm{C}$ ) that gelation is observed. Regarding the high- $q$ region, similar spectra have been reported in the literature of gel-forming systems: T. Lodge et al. analyzed aqueous solutions of high molecular weight methylcellulose ${ }^{17}$ similar structures were also found by Tung et al. for mixtures of low molecular lipids in aqueous solutions. ${ }^{18}$ Following these references, we found that SANS data recorded at $85{ }^{\circ} \mathrm{C}$ could be well fitted with a flexible cylinder model. ${ }^{19}$ The details of fitting are reported in Figure S11, a summary of results is presented in Table 2. Interestingly, this model based on SANS data in the organogel is reminiscent of the solid state structure found above by WAXD. In particular the diameter of the cylinders is increasing with the lengths of the alkyl side chains. When applying the same treatment to SANS data recorded at lower temperatures, we found that the same model remains valid with some variations in the parameters: the average radius is essentially constant, the Kuhn length is also almost constant 
for Alt-C18 but more fluctuating for Alt-C12, may be due to more pronounced aggregation, but always remains within 1 to 5 times the average diameter of the cylinders thus giving the picture of curly noddle like objects. Finally, the contour length was found to increase dramatically (as a result of low- $q$ upturn) when temperature was decreased, which is fully consistent with the establishment of a percolating gel of extended objects. In addition, investigations in an extended $q$ range were performed by SAXS for Alt-C18 (Figure S12 and Table S4). Basically SAXS data in the 0.01 to $0.5 \AA^{-1}$ range were well fitted with the same model as above. The parameters of the fit appear slightly different, probably due to the different origin of contrast for neutrons and X-rays, but their temperature dependence show the same trend: a major increase of the contour length when temperature is decreased. In addition, scattering data in the 0.001 to $0.01 \AA^{-1}$ range show a power law dependence: $I(q) \approx q$ ${ }^{3}$ which indicates the presence of large aggregates similar to what has already been observed in water-soluble fibrillar gelling systems. ${ }^{20}$

Cryo-TEM images of the Alt-C18 gel deposited from a $5 \mathrm{wt} \%$ cumene solution are presented in Figure 11. The left picture leaves the image of a rather uniform film featuring a densely packed felt morphology with a mesh size in the range of a few nanometers. Due to the small contrast between solvent and polymer, visible features may arise from surface rather than the bulk. The inner structure is more clearly revealed at the edge of a defect. The image on the right shows a tear of the film, caused by the radiation, there is clearly an interlace of fibers impregnated with solvent. The smallest features' width as measured on the picture is of about $4 \mathrm{~nm}$, in good agreement with the diameter given by the flexible cylinder model in SAXS analysis.

Thus, the morphologies revealed in this study illustrate the selfassembly induced by the alternating structure. In toluene, the solvophobic phenol groups segregate into elongated subdomains where they strongly associate via hydrogen bonds. The aggregates thereby formed, must have a helical or calixarene like structure, ${ }^{21}$ compatible with the connectivity of the polymer chain. Hydrocarbon chains, which have in contrast an excellent affinity with the solvent, occupy the periphery giving rise to an inverse micelle-like cylindrical morphology. At a larger scale, these elongated micelles appear highly agglomerated and interconnected giving rise to a felt like gel

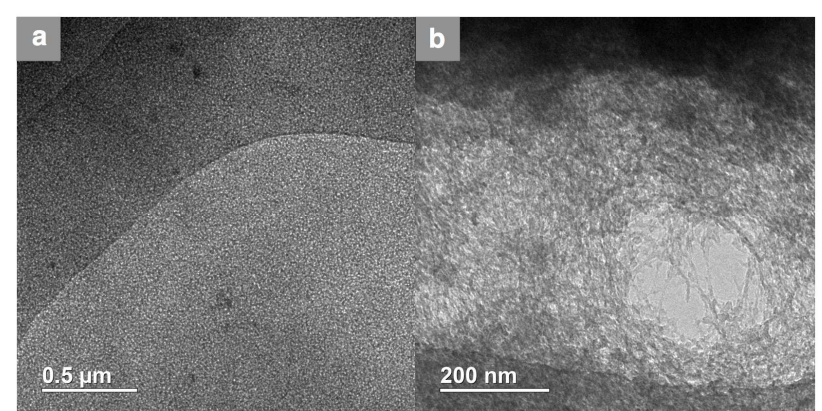

Fig 11. Cryo-TEM images of Alt-C18 at $5 w t \%$ in cumene. The left picture (a) is taken at the edge of the carbon grid. In the right picture (b), the fibrillar morphology is revealed inside a tear defect. morphology in which the excess solvent is trapped.

\section{Conclusions}

A series of alternating copolymers consisting of vinyl phenol and alkyl-pendant maleimide were synthesized via radical copolymerization and deprotection. Introduction of long alkyl chain into the maleimide unit gave thermosensitve solubility for diluted solution in aromatic solvent and hard gels when the concentration was increased. The gelation temperature and stiffness of the organogel are tuneable by varying concentration, solvent, molar mass and the length of the alkyl side chains. Some structural analyses with ${ }^{1} \mathrm{H}$ NMR, $\mathrm{X}$-ray, neutron scattering experiments and cryo-TEM gave the image of a fibrillar nanostructure with segregation phenol fragments from the hydrocarbon in the alternating sequence, in which the hydrogen bond interactions between phenol units are crucial.

\section{Conflicts of interest}

There are no conflicts to declare.

\section{Acknowledgements}

Michel Cloitre is thanked for setting up rheology experiments and for helpful discussions. Thomas Aubineau is thanked for performing preliminary NMR measurements. This work was partially supported by the French National Research Agency (ANR) and the Japanese Science and Technology Agency (JST) (ANR-15-JTIC-0004). Institut Laue-Langevin (ILL) Grenoble, is acknowledged for provision of beamtime. ${ }^{22}$ Lionel Porcar is thanked for his helpful contributions in experiments and data analyses. This research used resources of the Advanced Photon Source, a U.S. Department of Energy (DOE) Office of Science User Facility operated for the DOE Office of Science by Argonne National Laboratory under Contract No. DE-AC02-06CH11357. We thank Denis T. Keane of the Advanced Photon Source for his help in using beamline DND-CAT 5ID-D, S. Chappuis and T. Kondo for carrying out the measurements, Prof. Takaya Terashima (Kyoto University) and Dr. Ralm Ricarte (ESPCI) for their helpful suggestions in interpretations of data.

\section{Notes and references}

1 G. Moad, D. H. Solomon, The Chemistry of Radical Polymerization, Elsevier Science, Oxford, 2006, 2nd edn.

2 Z. M. O. Rzaev, Progress in Polymer Science, 2000, 25, 163-217.

3 B. Klumperman, Polymer Chemistry, 2010, 1, 558-562.

4 L. Leibler, Macromolecules, 1980, 13, 1602-1617.

5 G. Hattori, M. Takenaka, M. Sawamoto and T. Terashima, Journal of the American Chemical Society, 2018, 140, 8376-8379.

6 T. Alfrey and E. Lavin, Journal of the American Chemical Society, 1945, 67, 2044-2045. 
7 G. Q. Chen, Z. Q. Wu, J. R. Wu, Z. C. Li and F. M. Li, Macromolecules, 2000, 33, 232-234.

8 G. Moriceau, J. Tanaka, D. Lester, G. S. Pappas, A. G. Cook, P. O'Hora, J. Winn, T. Smith and S. Perrier, Macromolecules 2019, DOI: 10.1021/acs.macromol.8b02231

9 S. Srichan, D. Chan-Seng and J. F. Lutz, Acs Macro Letters, 2012, 1, 589-592.

10 M. Vargas, R. M. Kriegel, D. M. Collard and D. A. Schiraldi, Journal of Polymer Science Part a-Polymer Chemistry, 2002, 40, 3256-3263.

11 G. Moad, E. Rizzardo and S. H. Thang, Polymer, 2008, 49, $1079-1131$

12 S. Kim, H. Moon and J. Kim, Thermochimica Acta, 2015, 613, 9-16.

13 A. Skoulios, Adv. Colloid Int. Sci. 1967, 1, 79-110.

14 A. Pal, R. Das Mahapatra and J. Dey, Rsc Advances, 2014, 4, 7760-7765.

15 S. Pensec, F. G. Tournilhac, P. Bassoul and C. Durliat, Journal of Physical Chemistry B, 1998, 102, 52-60.

16 A. Guignier, Theorie et Technique de la Radiocristallographie, 2nd Ed. Dunod, Paris 1956, p 464.

17 J. R. Lott, J. W. McAllister, S. A. Arvidson, F. S. Bates and T. P. Lodge, Biomacromolecules, 2013, 14, 2484-2488.

18 C. Y. Cheng, H. Oh, T. Y. Wang, S. R. Raghavan and S. H. Tung, Langmuir, 2014, 30, 10221-10230.

19 J. S. Pedersen and P. Schurtenberger, Macromolecules, 1996, 29, 7602-7612

20 T. P. Lodge, A. L. Maxwell, J. R. Lott, P. W. Schmidt, J. W. McAllister, S. Morozova, F. S. Bates, Y. F. Li and R. L. Sammler, Biomacromolecules, 2018, 19, 816-824.

21 P. Opaprakasit, A. Scaroni and P. Painter, Journal of Molecular Structure, 2001, 570, 25-35.

22 F. Tournilhac, E. Cazares-Cortes, M. Ouchi, L. Porcar and B. Tarus, Institut Laue-Langevin (ILL), 2018, DOI: 10.5291/ILL-DATA.DIR-158. 


\section{Supporting Information}

\section{Physical Gelation of AB-Alternating Copolymers Made of Vinyl Phenol and Maleimide Units: Cooperation between Precisely Incorporated Phenol and Long Alkyl Pendant Groups}

Kana Nishimori, ${ }^{1}$ Esther Cazares-Cortes, ${ }^{2}$ Jean-Michel Guigner, ${ }^{3}$ Francois Tournilhac, ${ }^{2} *$ and Makoto Ouchi ${ }^{1 *}$

${ }^{1}$ Department of Polymer Chemistry, Graduate School of Engineering, Kyoto University, Katsura Nishikyo-ku, Kyoto 615-8510, Japan

${ }^{2}$ Molecular, Macromolecular Chemistry, and Materials, CNRS, ESPCI-Paris, PSL Research University, 10 rue Vauquelin 75005 Paris, France

${ }^{3}$ Institut de Minéralogie, de Physique des Matériaux et de Cosmochimie, Sorbonne Université, CNRS, UMR 7590, IRD, MNHN, 4 place Jussieu, F-75005 Paris, France

*Correspondence to: ouchi@living.polym.kyoto-u.ac.jp

*Correspondence to: francois.tournilhac@espci.fr

\section{Contents}

Table S1-S2. Characterization of alternating copolymers

Figure S1-S2. SEC curves and FT-IR spectra of alternating copolymers after deprotection

Figure S3-S5. ${ }^{1} \mathrm{H}$ NMR spectra of alternating copolymers before and after deprotection

Figure S6. MALDI-TOF-MS spectrum of Alt-C12

Figure S7. ${ }^{1} \mathrm{H}$ NMR spectra of $5 \mathrm{wt} \%$ Alt-C18 gel in toluene- $\mathrm{d}_{8}$ P17

Table S3. Viscosities of $5 \mathrm{wt} \%$ Alt-C12 solutions P18

Figure S8. DSC thermograms for bulk Alt-C12 and Alt-C18 P19

Figure S9. Chem3D molecular models for repeat unit of Alt-C12 and Alt-C18 P19

Figure S10. WAXD data of freeze dried Alt-C12 and Alt-C18

Figure S11. SANS data with fitting curves

Figure S12. SAXS data with fitting curves

Table S4. SAXS data of $5 \mathrm{wt} \%$ Alt-C18 solutions in toluene- $\mathrm{d}_{8}$ 
Table S1. Characterization of Alternating Copolymers with tBOS and $N$-Alkylmaleimides Synthesized by Free Radical Copolymerization

\begin{tabular}{ccrrcrcc}
\hline \multirow{2}{*}{ Entry $^{a}$} & \multirow{2}{*}{ MI Derivatives } & \multicolumn{2}{c}{ Conv., $\%^{b}$} & $\begin{array}{c}\text { Composition Ratio } \\
\text { tBOS/MI }\end{array}$ & $\begin{array}{c}M_{\mathrm{n}}{ }^{c} \\
\text { (GPC) }\end{array}$ & $\begin{array}{c}M_{\mathrm{w}} / M_{\mathrm{n}}{ }^{d} \\
\text { (GPC) }\end{array}$ \\
\hline 1 & C18MI & 97 & 98 & $49 / 51$ & 190000 & 3.44 \\
\hline 2 & C12MI & 98 & 99 & $49 / 51$ & 91900 & 6.45 \\
\hline 3 & C8MI & 96 & 100 & $49 / 51$ & 154200 & 2.46 \\
\hline 4 & C2MI & 93 & 99 & $50 / 50$ & 75300 & 5.33 \\
\hline
\end{tabular}

${ }^{a}$ Conditions: $[\mathrm{tBOS}]_{0} /[\mathrm{MI}]_{0} /[\mathrm{AIBN}]_{0}=1000 / 1000 / 20 \mathrm{mM}$ in toluene at $60{ }^{\circ} \mathrm{C}$ (Entries 1-4).

${ }^{b}$ Conversions of tBOS and MI derivatives were determined by ${ }^{1} \mathrm{H}$ NMR.

${ }^{c}$ Composition Ratio of tBOS and MI derivatives was determined by ${ }^{1} \mathrm{H}$ NMR after purification.

${ }^{d}$ Determined by GPC in THF with PSt standard calibration (before deprotection reaction).

Table S2. Characterization of Alternating Copolymers with tBOS and $N$-Dodecylmaleimide (C12MI) Synthesized by RAFT Polymerization

\begin{tabular}{|c|c|c|c|c|c|c|c|c|}
\hline \multirow[t]{2}{*}{ Entry $^{a}$} & \multicolumn{2}{|c|}{ Conc., mM } & \multicolumn{2}{|c|}{ Conv., $\%^{b}$} & \multirow{2}{*}{$\begin{array}{c}\mathrm{DP}^{c} \\
\text { (calcd.) }\end{array}$} & \multirow{2}{*}{$\begin{array}{c}\text { Composition Ratio }^{d} \\
\text { tBOS/C12MI }\end{array}$} & \multirow{2}{*}{$\begin{array}{c}M_{\mathrm{n}}{ }^{e} \\
(\mathrm{GPC})\end{array}$} & \multirow{2}{*}{$\begin{array}{c}M_{\mathrm{w}} / M_{\mathrm{n}}{ }^{e} \\
(\mathrm{GPC})\end{array}$} \\
\hline & tBOS & C12MI & tBOS & C12MI & & & & \\
\hline 1 & 1000 & 1000 & 95 & 97 & 190 & $49 / 51$ & 54300 & 1.32 \\
\hline 2 & 1000 & 1000 & 94 & 96 & 95 & $48 / 52$ & 31000 & 1.23 \\
\hline 3 & 500 & 500 & 90 & 91 & 45 & $49 / 51$ & 18700 & 1.20 \\
\hline 4 & 300 & 300 & 96 & 99 & 29 & $48 / 52$ & 12100 & 1.17 \\
\hline 5 & 100 & 100 & 100 & 100 & 10 & $50 / 50$ & 5100 & 1.11 \\
\hline
\end{tabular}

${ }^{a}$ Conditions: $[\mathrm{CTA}]_{0} /[\mathrm{AIBN}]_{0}=5 / 1 \mathrm{mM}$ (Entry 1) and $10 / 1 \mathrm{mM}$ (Entries 2-5) in toluene at $60{ }^{\circ} \mathrm{C}$.

${ }^{b}$ Conversions of tBOS and C12MI were determined by ${ }^{1} \mathrm{H}$ NMR.

${ }^{c}$ The average DPs of tBOS and C12MI in copolymers were determined by monomer conversions.

${ }^{d}$ Composition Ratio of tBOS and C12MI was determined by ${ }^{1} \mathrm{H}$ NMR after purification.

${ }^{e}$ Determined by GPC in THF with PSt standard calibration (before deprotection reaction). 


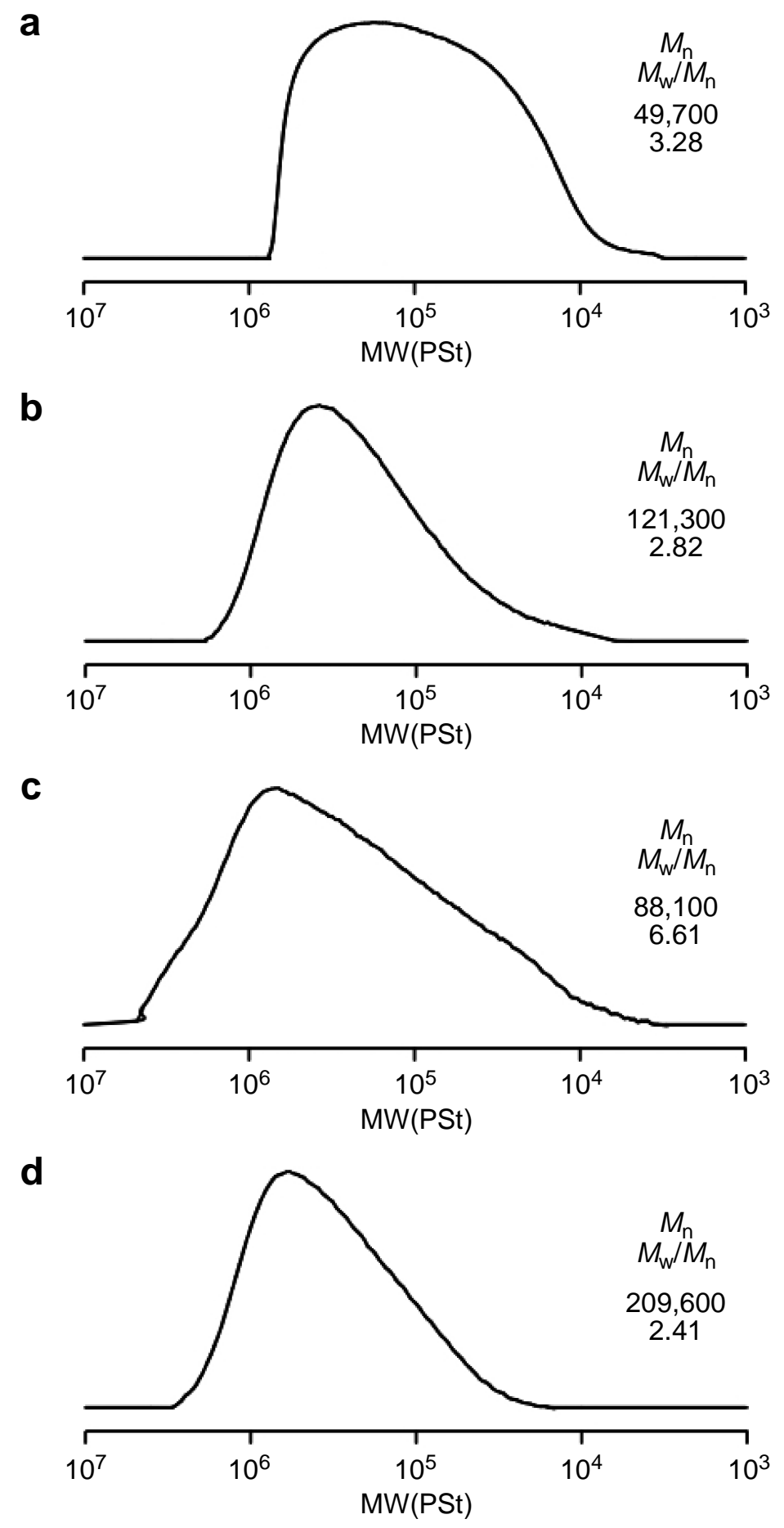

Figure S1. SEC curves of (a) Alt-C2, (b) Alt-C8, (c) Alt-C12 and (d) Alt-C18 in THF. 
a

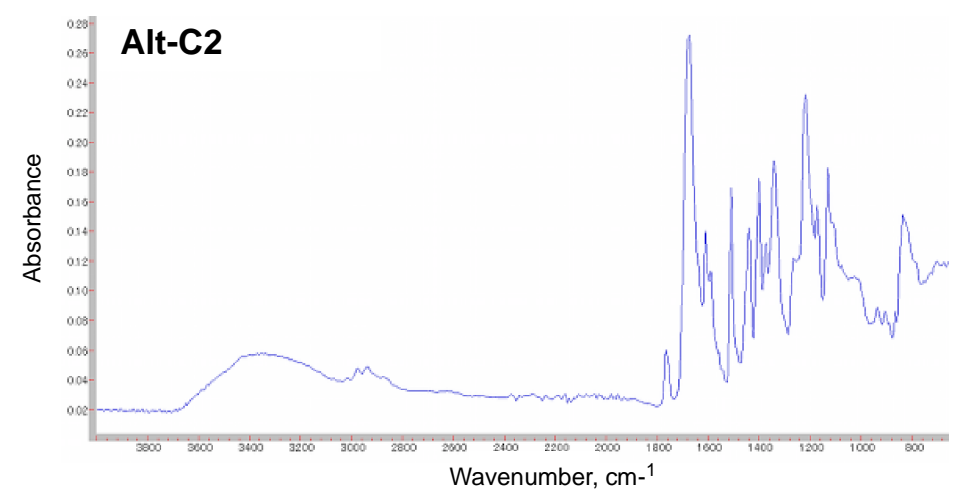

b

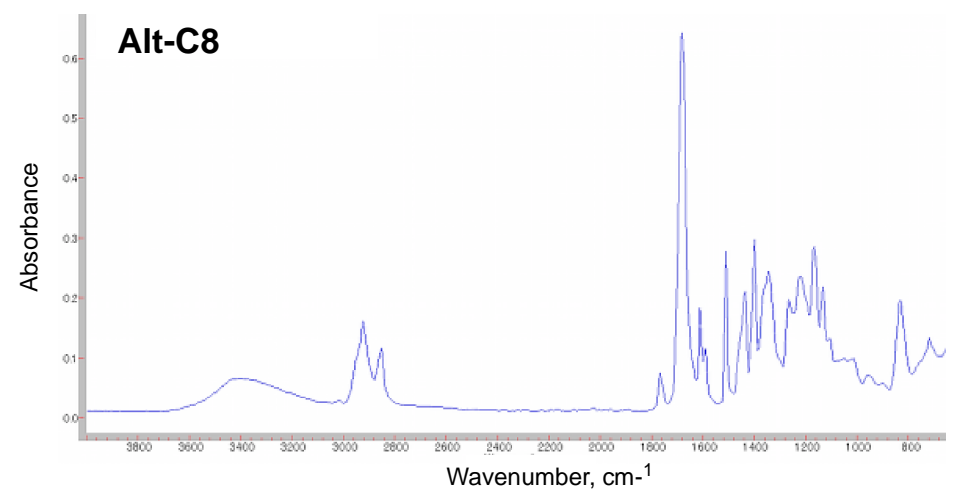

C
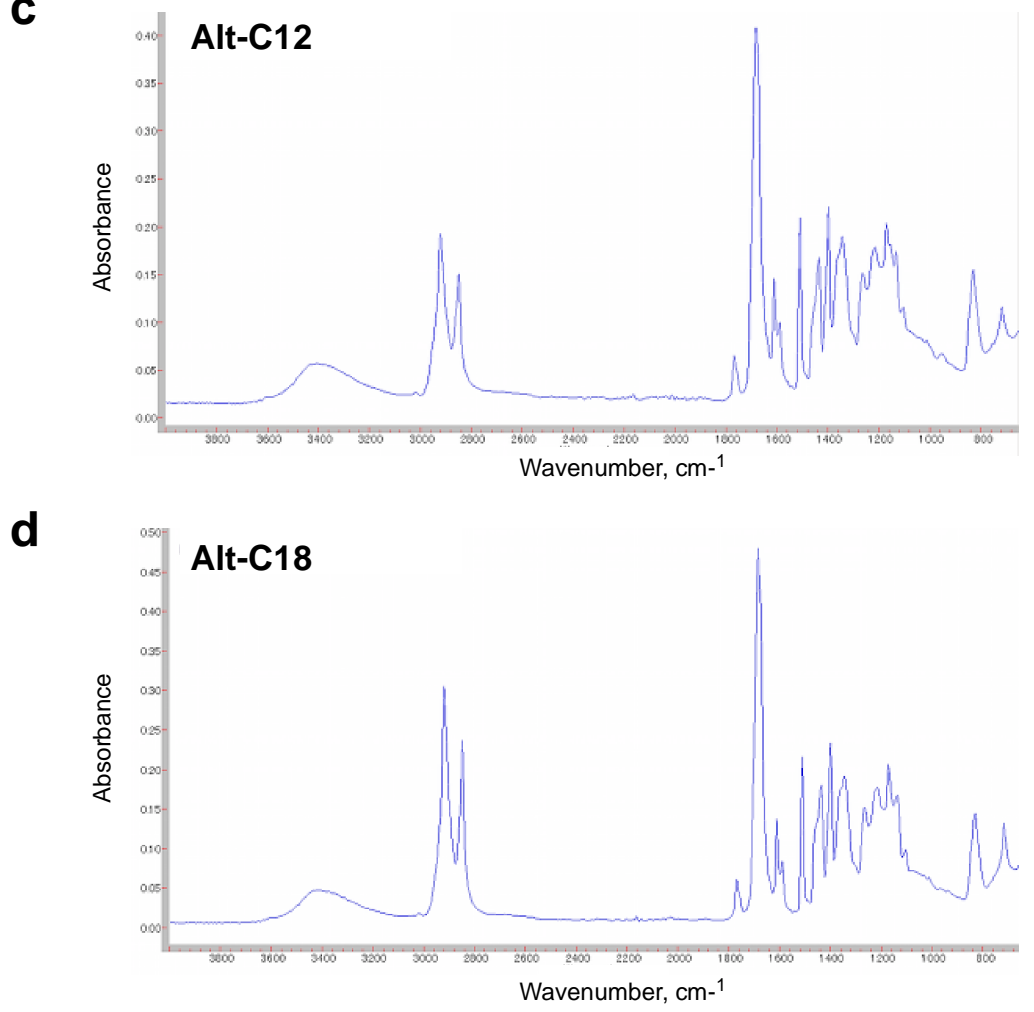

Figure S2. FT-IR spectra of (a) Alt-C2, (b) Alt-C8, (c) Alt-C12 and (d) Alt-C18. 

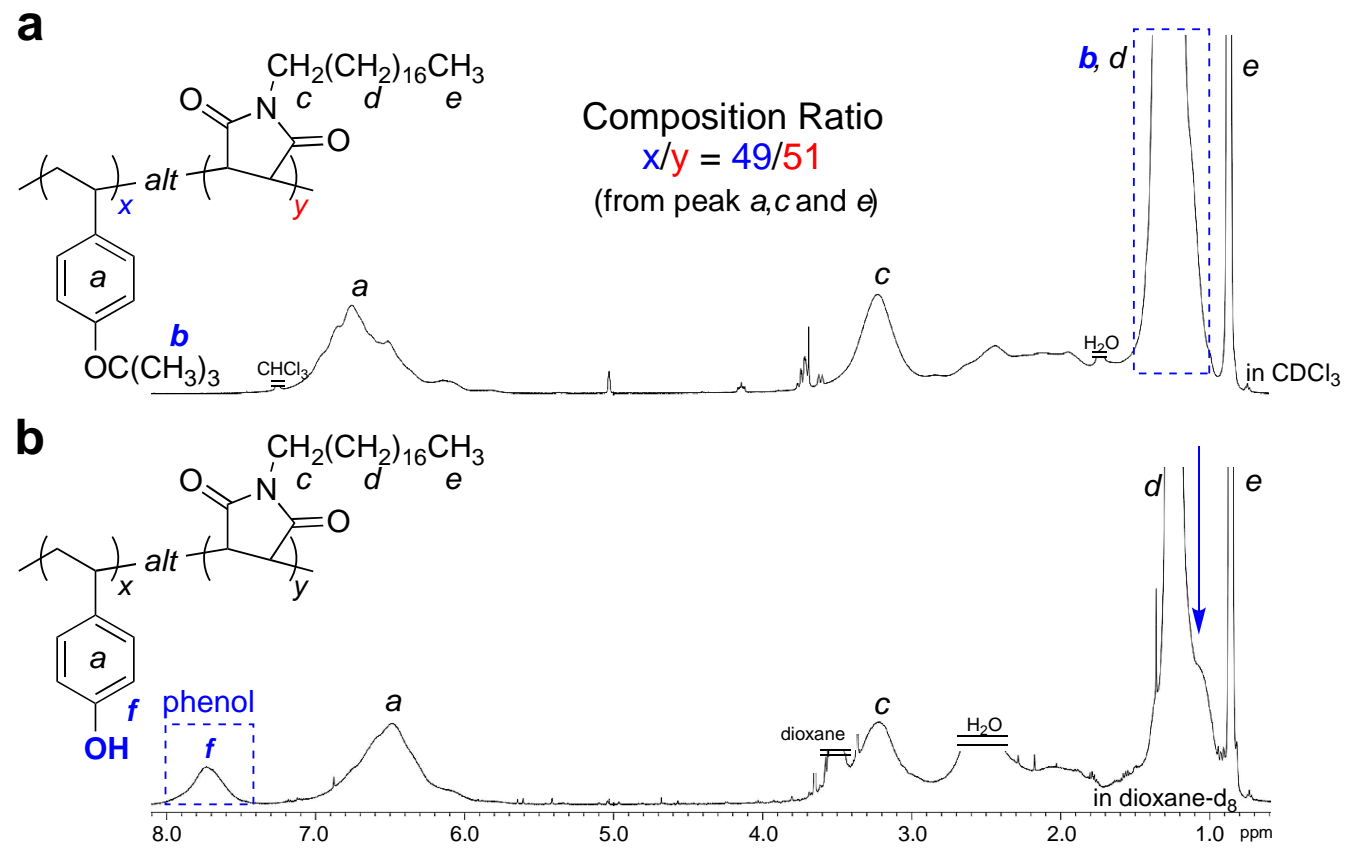

Figure S3. ${ }^{1} \mathrm{H}$ NMR spectra of the copolymer with tBOS and C18MI (a, $\mathrm{CDCl}_{3}$ ) and the copolymer after deprotection reaction (b, 1,4-dioxane- $\left.\mathrm{d}_{8}\right)$.

a



Figure S4. ${ }^{1} \mathrm{H}$ NMR spectra of the copolymer with tBOS and C8MI (a, $\mathrm{CDCl}_{3}$ ) and the copolymer after deprotection reaction $\left(b\right.$, acetone- $\left.d_{6}\right)$. 


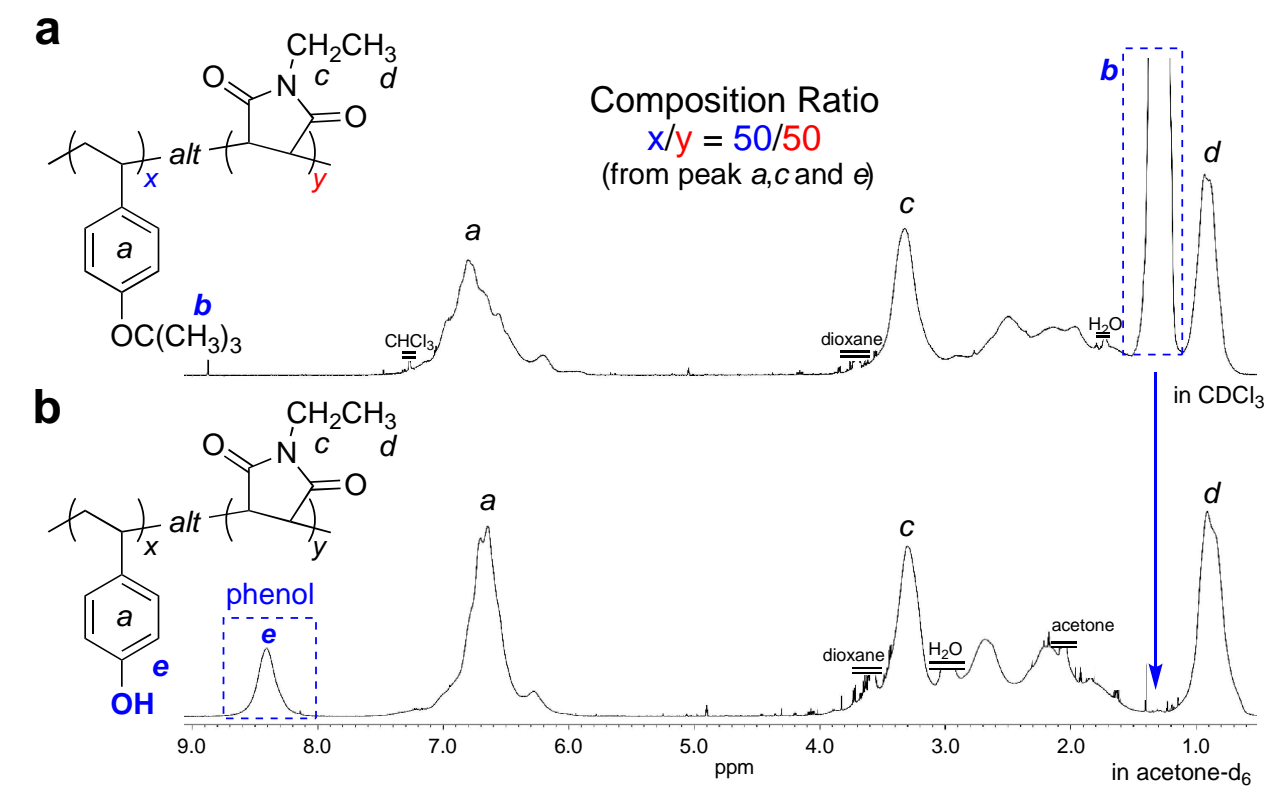

Figure S5. ${ }^{1} \mathrm{H}$ NMR spectra of the copolymer with tBOS and $\mathrm{C} 2 \mathrm{MI}\left(\mathrm{a}, \mathrm{CDCl}_{3}\right)$ and the copolymer after deprotection reaction (b, acetone- $\left.\mathrm{d}_{6}\right)$.



Figure S6. MALDI-TOF-MS spectrum of Alt-C12 $\left(M_{\mathrm{n}}=18200, M_{\mathrm{w}} / M_{\mathrm{n}}=1.22\right)$ synthesized by RAFT copolymerization. 


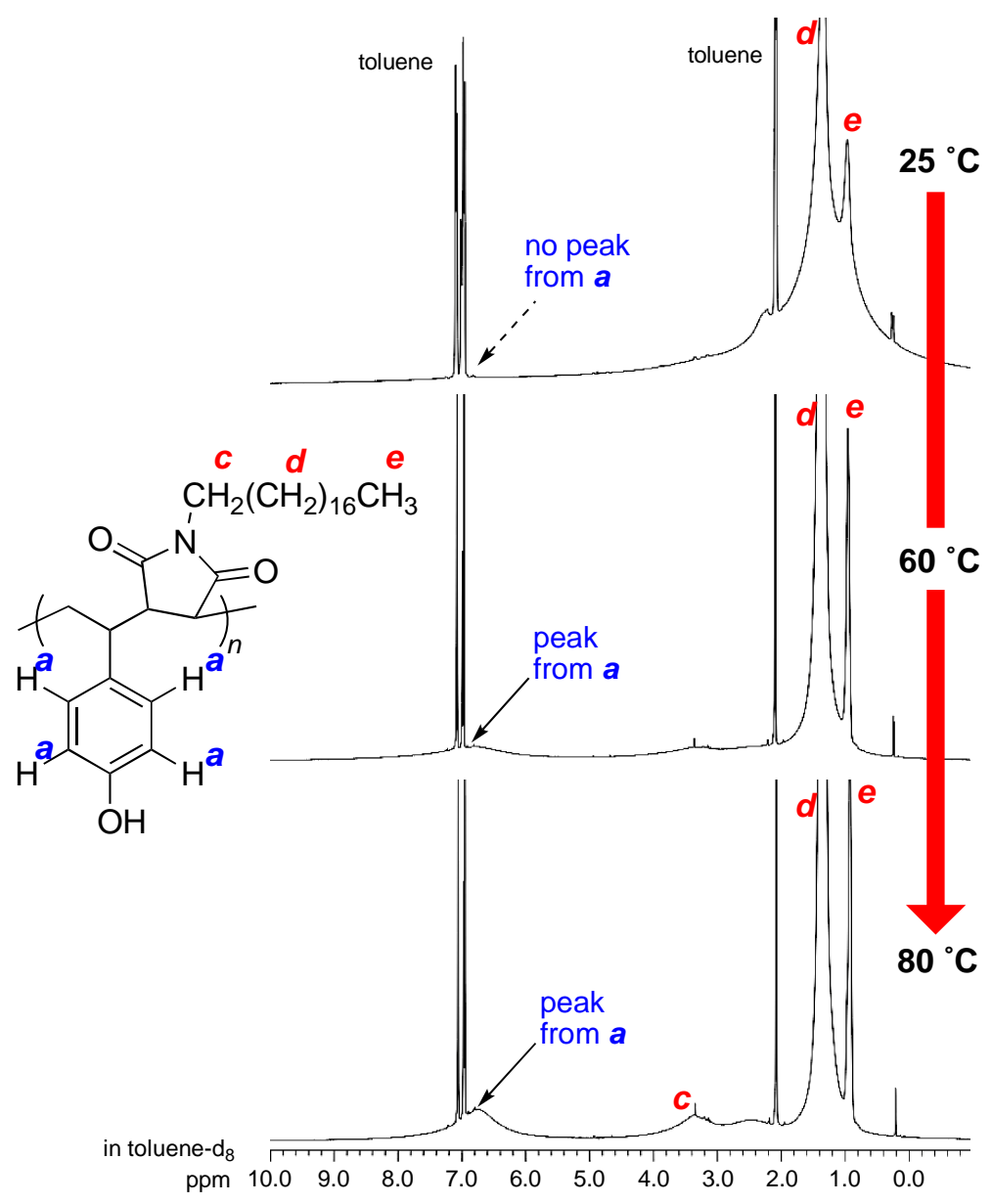

Figure S7. ${ }^{1} \mathrm{H}$ NMR spectra of $5 \mathrm{wt} \%$ Alt-C18 gel in tolunene-d $\mathrm{d}_{8}$ at $25{ }^{\circ} \mathrm{C}, 60{ }^{\circ} \mathrm{C}$ and $80{ }^{\circ} \mathrm{C}$. 
Table S3. Viscosity of the Solution of Alt-C12 in Toluene (5wt\%) After Addition of Pyridine in Comparison with the Solution in THF (5wt\%)

\begin{tabular}{|c|c|c|}
\hline \multirow{2}{*}{ Angle ( $\left.{ }^{\circ}\right)$} & \multicolumn{2}{|c|}{ Viscosity $(\mathbf{m P a} \cdot \mathbf{s})$} \\
\hline & $\begin{array}{c}\text { In Toluene } \\
\text { After Addition of Pyridine }{ }^{a}\end{array}$ & In THF \\
\hline 20 & 8.35 & 10.19 \\
\hline 25 & 8.29 & 10.17 \\
\hline 30 & 8.26 & 10.22 \\
\hline 35 & 8.29 & 10.25 \\
\hline 40 & 8.33 & 10.32 \\
\hline 45 & 8.36 & 10.39 \\
\hline 50 & 8.41 & 10.44 \\
\hline 55 & 8.44 & 10.50 \\
\hline 60 & 8.48 & 10.53 \\
\hline 65 & 8.46 & 10.51 \\
\hline 70 & 8.36 & 10.40 \\
\hline Average & 8.37 & 10.36 \\
\hline
\end{tabular}

${ }^{a}$ The amount of pyridine added in toluene solution was 2 equimolar with phenol groups in the solution. 
a



b

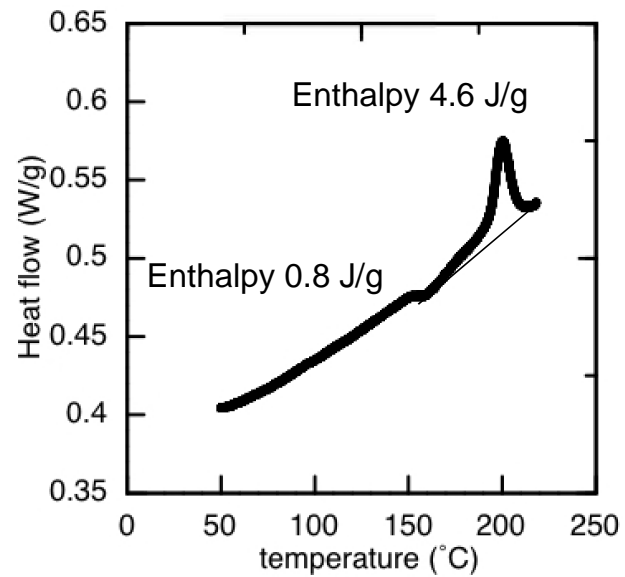

Figure S8. DSC thermograms recorded at 2nd heating process for bulk samples of (a) Alt-C12 and (b) Alt-C18. Temperature program: 1st heating at $10{ }^{\circ} \mathrm{C} / \mathrm{min}$ from $20{ }^{\circ} \mathrm{C}$ to $250{ }^{\circ} \mathrm{C} ; 5 \mathrm{~min}$ holding at $250{ }^{\circ} \mathrm{C} ; 1$ st cooling at $10{ }^{\circ} \mathrm{C} / \mathrm{min}$ from $250{ }^{\circ} \mathrm{C}$ to $20{ }^{\circ} \mathrm{C} ; 2$ nd heating at $10{ }^{\circ} \mathrm{C} / \mathrm{min}$ from $20{ }^{\circ} \mathrm{C}$ to $250{ }^{\circ} \mathrm{C}$.

a $22 \AA$
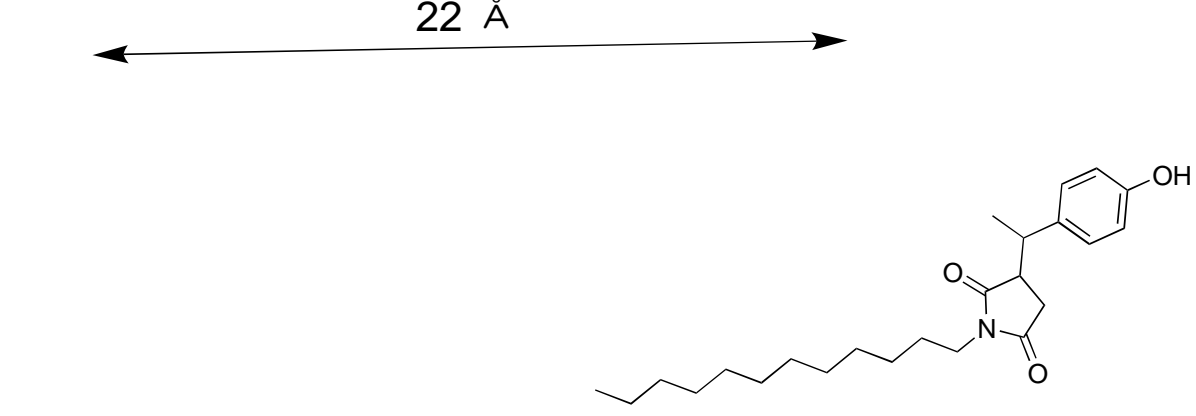

b

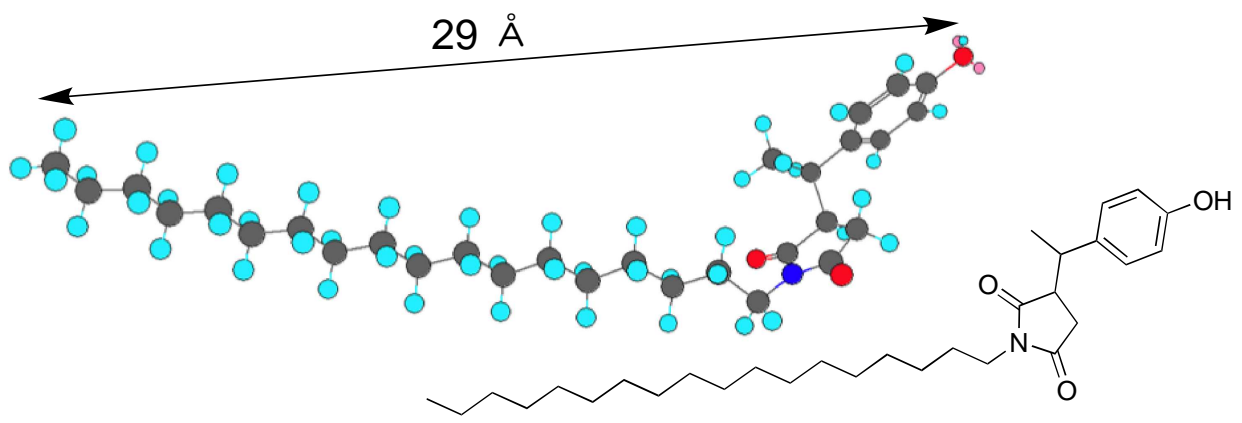

Figure S9. Chem3D Molecular models of dimers of 4-vinylphenol and $\mathrm{N}$-alkylmaleimide (a, C12MI; b, C18MI) with alkyl chains in the fully extended conformation. 
a

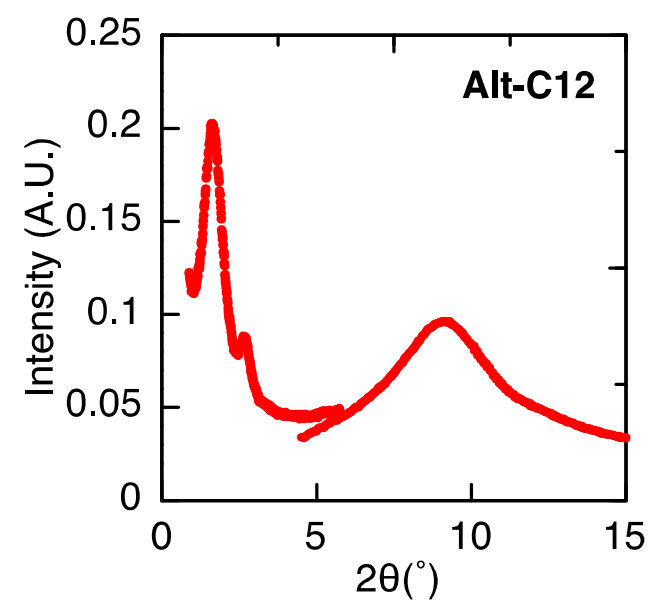

b

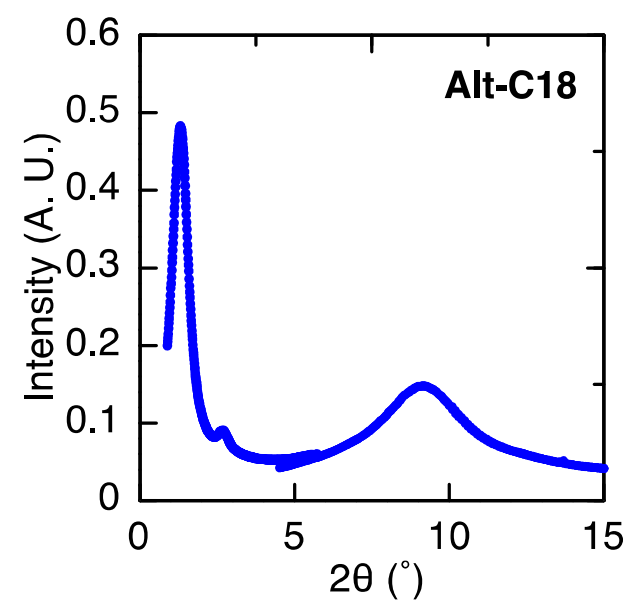

Figure S10. Wide angle X-ray diffraction patterns of freeze dried bulk Alt-C12 (a) and Alt-C18 (b). The peak arising at $2 \theta=2.7^{\circ}$ is due to Kapton windows. 
a



b

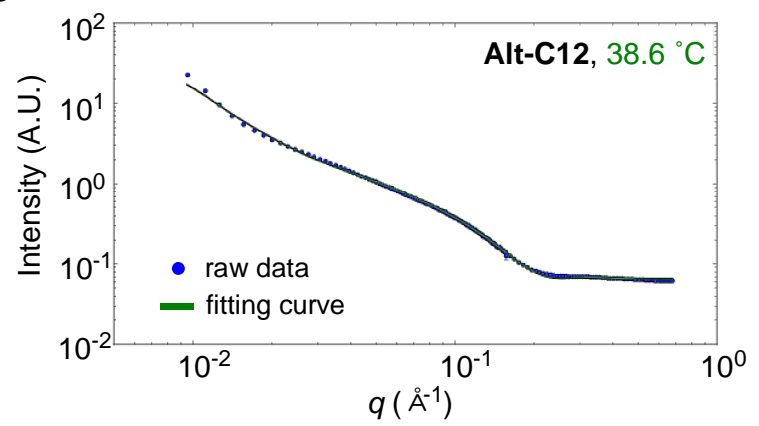

C

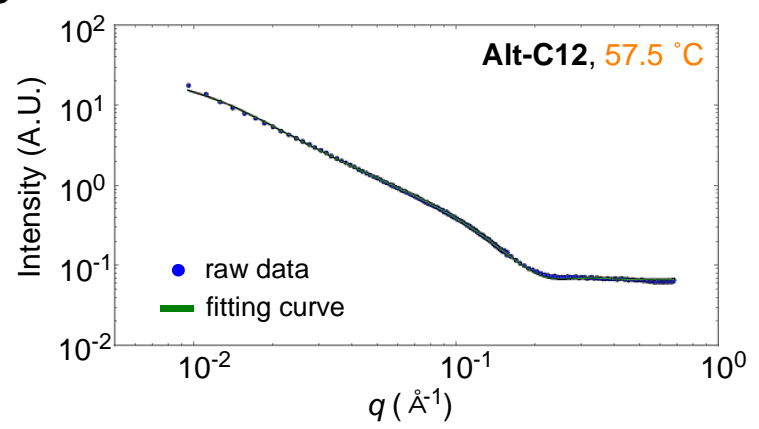

d



e

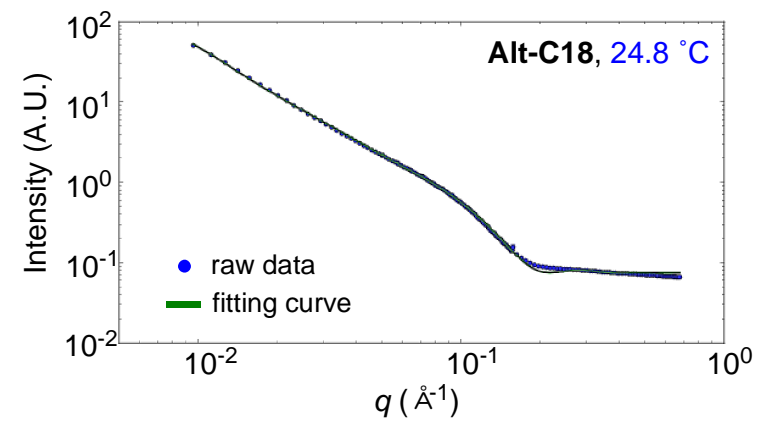

f

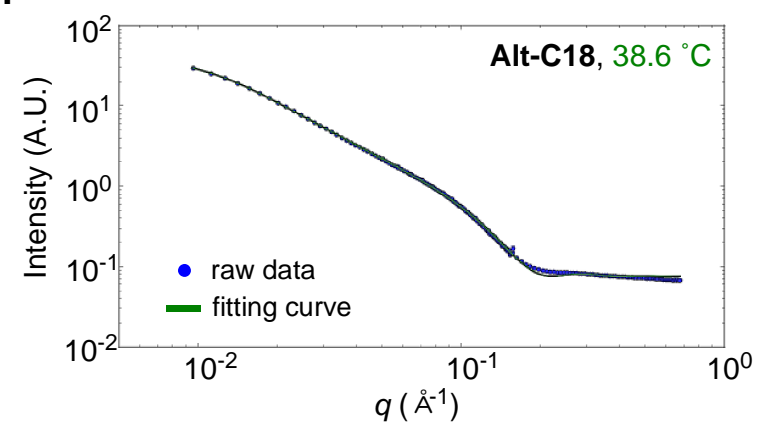

g

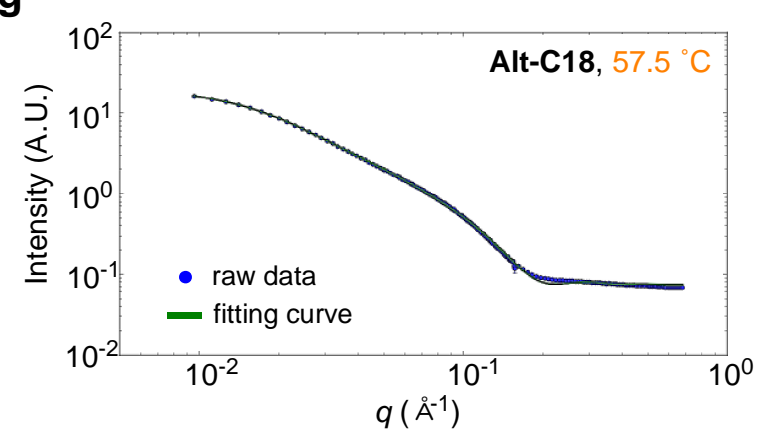

h

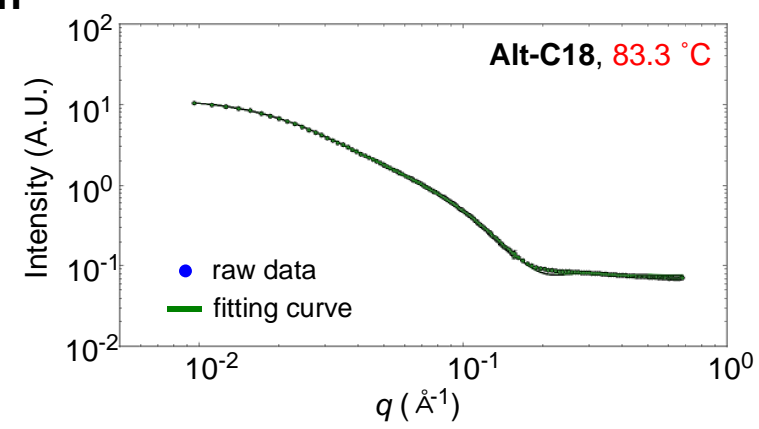

Figure S11. SANS data with fitting curves for Alt-C12 (a-d) and Alt-C18 (e-f). 



Figure S12. SAXS data with fitting curves for Alt-C18 (a-d) at different temperatures. The fitting curve1 (green) correspond to a flexible cylinder model fitted from 0.01 to $0.5 \AA^{-1}$. The fitting curve 2 (red) correspond to a shape unique power law model fitted from 0.001 to $0.01 \AA^{-1}$. 
Table S4. Fitting Parameters from Modeling of SAXS Data Recorded at Various Temperatures

\begin{tabular}{|c|c|c|c|c|c|c|c|}
\hline \multirow[t]{2}{*}{$\overline{\text { Sample }}$} & \multicolumn{5}{|c|}{ flexible cylinder } & \multicolumn{2}{|c|}{ power law } \\
\hline & $\begin{array}{c}\text { Temperature } \\
\left({ }^{\circ} \mathbf{C}\right)\end{array}$ & $\begin{array}{c}\text { Av. Radius } \\
(\AA)\end{array}$ & $\begin{array}{c}\text { Kuhn } \\
\text { length }(\AA)\end{array}$ & $\begin{array}{c}\text { Contour } \\
\text { length (Å) }\end{array}$ & $\begin{array}{c}\text { Background } \\
\left(\mathrm{cm}^{-1}\right)\end{array}$ & power & $\begin{array}{c}\text { Background } \\
\left(\mathrm{cm}^{-1}\right)\end{array}$ \\
\hline \multirow[t]{4}{*}{$\overline{\text { Alt-C18 }}$} & 84 & 8.48 & 140.4 & 429.0 & 0.12 & 3.19 & 4.11 \\
\hline & 56 & 8.51 & 103.4 & 634.6 & 0.12 & 3.17 & 5.23 \\
\hline & 39 & 8.50 & 76.0 & 1092.5 & 0.05 & 3.03 & 6.87 \\
\hline & 25 & 8.50 & 58.3 & 4000.0 & 0.05 & 2.80 & 21.96 \\
\hline
\end{tabular}

of $5 \mathrm{wt} \%$ Alt-C18 Solutions in Toluene- $\mathrm{d}_{8}$ 